\title{
Enzymatic crosslinked hydrogels for biomedical application
}

\author{
Elham Badali ${ }^{1}$, Maryam Mohajer ${ }^{2}$, Sajad Hassanzadeh ${ }^{2}$, Sepideh Saghati ${ }^{3}$, Mehdi \\ Khanmohammadi ${ }^{2 *}$
}

\begin{abstract}
${ }^{1}$ Faculty of Chemistry, Kharazmi University, P. O. Box 15719-14911, 49 Mofateh St., Tehran, Iran

${ }^{2}$ Skull Base Research Center, The Five Senses Institute, Hazrat Rasoul Akram Hospital, Iran University of Medical Sciences (IUMS), Tehran, Iran

${ }^{3}$ Department of Tissue Engineering, Faculty of Advanced Medical Sciences, Tabriz University of Medical Sciences, Tabriz, Iran
\end{abstract}

\section{Corresponding author:}

Mehdi Khanmohammadi, Skull Base Research Center, The Five Senses Institute, Hazrat Rasoul Akram Hospital, Iran University of Medical Sciences (IUMS), Tehran, Iran

Email: mehdi.khanmohammadi84@gmail.com \& khanmohammadi-mehdi@iums.ac.ir

\section{Acknowledgment}

We thank Iran University of Medical Sciences for the financial support with grant number

\section{Data availability statement}

Research Data are not shared. 


\begin{abstract}
Self-assembled structures mostly arises through enzyme-regulated phenomena in nature under persistent conditions. Enzymatic reactions are one of main biological processes in fabrication and construction of supramolecular hydrogel networks required for biomedical applications. The enzymatic processes provide a unique opportunity to integrate hydrogel formation. In most of cases, structure and substrates of hydrogels are adjusted by enzyme catalysis due to the chemo-, regio- and stereo-selectivity of enzymes. Hydrogels processed by using various enzyme schemes showed remarkable characteristics as dynamic frames for cells, bioactive molecules and drugs in biomedical applications. A novel class of enzyme-mediated crosslinking hydrogels mimics the extracellular matrices by displaying unique physicochemical properties and functionalities like water-retention capacity, drug loading ability, biodegradability, biocompatibility, biostability, bioactivity, optoelectronic properties, self-healing ability, shape memory ability. In recent years, many enzymatic systems investigated hydrogel cross-linking. Results of biocompatible hydrogel products show that these mechanisms of crosslinking can fulfill requirements for variety of biomedical applications including tissue engineering, wound healing and drug delivery.
\end{abstract}

\title{
Keywords
}

Enzymatic reaction; crosslinking; Hydrogel; Biomedical application; Tissue engineering; Wound healing; Drug delivery

\section{Introduction}

Most of cells in the body are placed in a three-dimensional (3D) microenvironment $(1,2)$. The organization and geometry of these 3D structures have a great effect on the cellular 
charactristics incuding function, bahaviour, metabolism, and fate $(3,4)$. By designing biomimetic 3D microenvironement through biocompatible reactions and biomaterials can profound insights into the responsible complex, mechanical and biochemical interactions, and in following fundamental biological processes (5). These new developments in the creation of cultured systems are required in drug discovery, regeneration of malignant or damaged tissues and analy analysis of biological processes. As all fields of biomedicine and biotechnology are strongly influenced by these achievements $(1,2,6)$. The purpose of tissue engineering (TE) is to produce artificial tissues and organs that can demonstrate native processes and functions $(7,8)$. To this end, fabricated scaffolds with or without cells are delivered to the injured or diseased body tissues and organs. Afterward, implanted tissue construct regenerates a new tissue either by its degradation and synthesis of new tissue from the embedded cells or by stimulating the host cells $(2,9)$. The design and fabrication of scaffold substrates is extremely complicated due to the variation and complexity of the prospective applications $(2,6,10)$. Nevertheless, several essential requirements in fabrication of all 3D architecture need to achieve. First, all incorporated substrated and applied treating methods have to be biocompatible and . Endurement under the mechanical loads and sustaining mechanical uniformity and integrity of fabricated structures are second item in design process. Third, the microstructure of the hydrogel should facilitate cellular adhesion, and ideally, integrate into the surrounding biological microenvironment. Finally, highly porous systems are necessary to enable cellular migration and proliferation as well as the growth of surrounding tissue and angiogenesis(11-13). Other important considerations are the controlled stimulation of the predictable cellular responses, for example, proliferation, migration, organization, and differentiation (12-15). These complex requirements, in addition to the need for easy and convenient sterilization, handling, and 
processing procedures of all included materials, make the process further complicated (16-18). In recent years, numerous synthetic, natural, inorganic, and their combinations have been used to develop scaffolds $(7,8,19)$. Hydrogels are crosslinked polymeric networks capable of retaining high quantity of water. Both natural and synthetic polymers have been used to form hydrogels. The polymers are crosslinked through either physical interactions or chemical bonds, resulting in a network that swells in the water while maintaining a defined 3D structure. $(1,3,6)$. The high water content results in a transparent material, which is an important characteristic in the development of hydrogels for applications such as contact lens composed of crosslinked poly (hydroxyethyl methacrylate) (pHEMA) and polyvinyl alcohols (PVA) (3, 4). Because hydrogels have a similar architecture to the extracellular matrix and soft tissues in terms of their rubbery nature, they cause little mechanical and frictional irritation to the surrounding tissues when implanted in the body $(2,6,20)$. Also, the 3D network hydrogels provide structural support and enable the oxygen, nutrients, and metabolites transportation to and from the encapsulated cells (21-23). Therefore, hydrogels were further explored for in vivo applications, and their examples are a coating material on the inner surface of blood vessels to minimize thrombosis following surgery-induced tissue injuries (5) or as a barrier between tissues to prevent postoperative adhesion formation $(6,24)$. Furthermore, the drug delivery can be magnetically triggered and actuated via the incorporation of magnetic moieties into the carrier system $(23,25)$. Biofabrication techniques and micrometer-sized cell-containing hydrogel vehicles generated via emulsification methods are both new uprising approaches in this field (26-28). Besides, these substrates are promising candidates for 3D printing and bioplotting processes because of their high viscosity of polymeric precursor solutions and their rapid gelation in the presence of appropriate cues (29). In the case in which the precise site's dimensions of a defect or injured 
tissue are not accessible or too complex to be fabricated, injectable hydrogels are the proper choice $(2,24,30)$. The injection of a hydrogel precursor solution and the subsequently triggered network formation are the flexible nature of hydrogels, which can adapt hydrogels to the given environmental conditions. Injured tissue sites can be filled in a rapid and convenient way with minimal invasion from the host immune system $(2,24,30)$. Furthermore, the chemical and physical properties of the hydrogels are adjustable, for example, the network structure and pore size of the hydrogel constructs can be tuned and customized for a given application by controlling parameters such as the chemical composition and crosslinking methodologies (2, 31).

Many hydrogel cross-linking approaches, including physical and chemical, have been employed to form polymer networks depending on the required structure and desired application $(1,2)$. Physically cross-linked hydrogels are formed through changes in environmental conditions whereby gelation often occurs under the influence of $\mathrm{pH}$, temperature, polyelectrolyte complexation, hydrogen bonding, crystallization, and hydrophobic association (1-6). Chemically cross-linked hydrogels comprising covalent bonds among the polymer chains are formed via radical polymerization and non-enzymatic or enzymatic cross-linking of complementary groups (7-10). Comparing existing physical and chemical approaches, enzyme-mediated hydrogel formation is proven to be mild and effective, therefore development of this approach with higher degrees of complexity is a current focus (Table 1) $(1,9)$. The majority of enzymes involved in hydrogel cross-linking are common to enzymes that catalyze reactions in our body. Enzymatic reactions that occur at neutral $\mathrm{pH}$, in aqueous solutions, and at physiological temperatures, are highly desired for biomedical applications. Moreover, possible cytotoxic consequences and unexpected by-products that can arise with the use of photo-initiator- or organic solvent- 
mediated reactions are avoided as a result of substrate specificity of the enzyme $(8,11,12)$. Another more noteworthy advantage relates to mildness of the enzymatic reaction under normal physiological conditions, because this method for cross-linking natural polymers cannot withstand harsh chemical conditions leading to loss of bioactivities $(8,13)$. Lastly, the use of enzymatic cross-linked hydrogels offers prospective for employing a variety of enzymatic systems to choose the desired hydrogel properties for different biomedical purposes $(11,12,14)$. This review selected the enzyme-mediated cross-linking method for hydrogel production as the template material for engineering tissue and regenerative medicine because this approach has emerged as a desirable alternative pathway to overcome the difficulties associated with chemical cross-linking methods.

Table 1. Advantages and drawbacks of different cross-linking methods for producing hydrogels $(11,12$, 14).

\begin{tabular}{|c|c|c|}
\hline & Advantages & Drawbacks \\
\hline $\begin{array}{l}\text { Physical cross-linking (e.g., ionic, } \\
\text { electrostatic, protein and } \\
\text { hydrophobic interactions, hydrogen } \\
\text { bonding, crystallization, and } \\
\text { thermo-responsive) }\end{array}$ & $\begin{array}{ll}- & \text { Reversibility } \\
\text { - } & \text { Absence of potentially } \\
& \text { harmful chemical } \\
& \text { reactions } \\
\text { - } & \text { Homogeneous cross- } \\
& \text { linking }\end{array}$ & $\begin{array}{ll}\text { - } & \text { No sufficient } \\
\text { - } & \text { Unstable } \\
\text { - } & \text { Lack of tailorability } \\
\text { - } & \text { Inflammatory due to } \\
\text { changes in ion } \\
\text { concentration and } \mathrm{pH}\end{array}$ \\
\hline $\begin{array}{l}\text { Chemical cross-linking (e.g., } \\
\text { radical, polymerization, photo- } \\
\text { crosslinking, organic solvents- } \\
\text { mediated reactions) }\end{array}$ & $\begin{array}{ll}\text { - } & \text { Covalent bonds } \\
\text { - } & \text { Controllable mechanical } \\
\text { strength } \\
\text { - } & \text { Superior physiologic } \\
\text { stability }\end{array}$ & $\begin{array}{ll}\text { - } & \text { Undesired side reactions } \\
\text { - } & \text { Toxic reagents } \\
\text { - } & \text { Harsh conditions } \\
\text { - } & \text { Cluster formation }\end{array}$ \\
\hline
\end{tabular}




\begin{tabular}{llll}
\hline Enzyme-mediated cross-linking & $\bullet$ & In situ gelation & $\bullet \quad$ Substrate specificity \\
& $\bullet$ & Substrate specificity & $\begin{array}{l}\text { (cross-linking reaction occurs } \\
\text { only between the enzyme- } \\
\text { specific polymers }\end{array}$ \\
& - No toxic by product & \\
& - Neutral pH & \\
& - Moderate temperature
\end{tabular}

\section{Transglutaminase (TG)}

Transglutaminases (TGs) are a broad family of thiol enzymes that catalyze post-translational protein modification mostly by inducing isopeptide bond configuration. The covalent conjugation of polyamines, lipid esterification, or the deamination of glutamine residues is also other candicates for this purpose. The TGs are a mild substitute for chemical crosslinking, which catalyze the formation of covalent bonds between a free amine group from a protein or a peptidebound lysine and the g-carboxamide group of proteins or peptide-bound glutamine (Fig. 1) (12, 15). The TGs mostly originate from both microbial (16) and mammalian cells (17). Davis et al. developed a protein-based hydrogel system that was cross-linkable by TG (18). This system consists of two de novo designed protein polymers named Kn and BQ, where the Kn block contains lysines, B is a random coil hydrophilic block, and Q block serves as a glutamine substrate (19). Residues are formed, once isopeptide is bonded between glutamine and lysine. These bonds are highly resistant to proteolytic degradation. As a result, steady polymeric networks are assembled, without any addition of co-factors. The biochemical function of TGs was revealed by discovering the role of isozyme factor XIII in blood coagulation for fibrinstabilizing factor (20). These enzymes exist in a variety of tissues such as skin and brain tissues 
(21-23). The TGs are essential for formation of fibrin clots and cornified epidermis. Consequently, the lack of these enzymes strictly hampers wound healing (24). Davis et al. has reported a modular hydrogel with tunable characteristics that was formed within 2 min by using this system. Also, bioactive peptides allows customizable cell-signaling requirements when engrafted. Fibrin matrices are formed by factor XIII, which is the circulatory form of transglutaminases (18). Several applications have been studied both in vitro and in vivo for these matrices, including angiogenesis, nerve repair, and cartilage tissue engineering (25-28). Sala et al. used activated transglutaminase factor XIIIa which is fibrin stabilizing factor to simultaneously couple site-specific cell adhesion ligands and crosslink modified multi-arm poly (-ethylene glycol) (PEG) precursors. In their system, the material building blocks are responsive to two enzymatic systems, one responsible for matrix formation and the other one for degradation process (29). The enzyme-mediated site-specific coupling of ligands allowed enhanced cell spreading, proliferation, and migration, as well as proteolytic matrix degradation by cell-derived matrix metalloproteinases (MMPs). Well-designed strategies also used factor XIIIa to crosslink star-shaped PEG, functionalized by either a glutamine acceptor or donor, to bind growth factors to surfaces that were provided (29). Consecutive enzymatic reactions permit for site-specific immobilization of large quantities of biologically active substances. Tissue transglutaminase has a high degree of sequence similarity with other transglutaminases, such as factor XIII, however it doesn't require any proteolysis for activation. Furthermore, tissue TGs show stronger adhesiveness than fibrin-based glues and less vulnerability to physical parameters like humidity (30). Sperinde and Griffith described the combination between PEG and tissue TGs. In their models, the gelation time depended on polymer functionalities, primary stoichiometric ratios, and substrate kinetics $(31,32)$. Hu and Messersmith reported the high adhesive strength of the in 
situ formed peptide conjugated polymer hydrogels cross-linked by TG (33). The TG has also been used to create gelatin-based hydrogels. These gels can be used for the incorporation of the cells with excellent cytocompatibility, which is a superior characteristic for TE applications. Additionally, they show great transport properties, which assist in sustained drug delivery (34, 35). Genetically engineered elastin-like polypeptide hydrogels and peptide-PEG conjugates cross-linked by transglutaminases have shown hopeful features as injectable hydrogels or cartilage repair $(36,37)$. In the report published by Jones et al., reactive ECM components recognized that these could be allowed the coupling of peptide and peptide-polymer conjugates via tissue TG. The possibility to broaden the application of this strategy to a variety of tissue surfaces highlights the flexibility of this method for biomedical applications. Using this method, surfaces can be modified with molecules such as functional moieties, growth factors, or therapeutic drugs. The TGs are enzymes that depend on the presence of $\mathrm{Ca}^{2+}(37)$. The $\mathrm{Ca}^{2+}$ independent TG-catalyzed gel formation also represented the ability to entrap and release the cells. These gels come into view particularly practical for microfluidic biosensor systems (38).

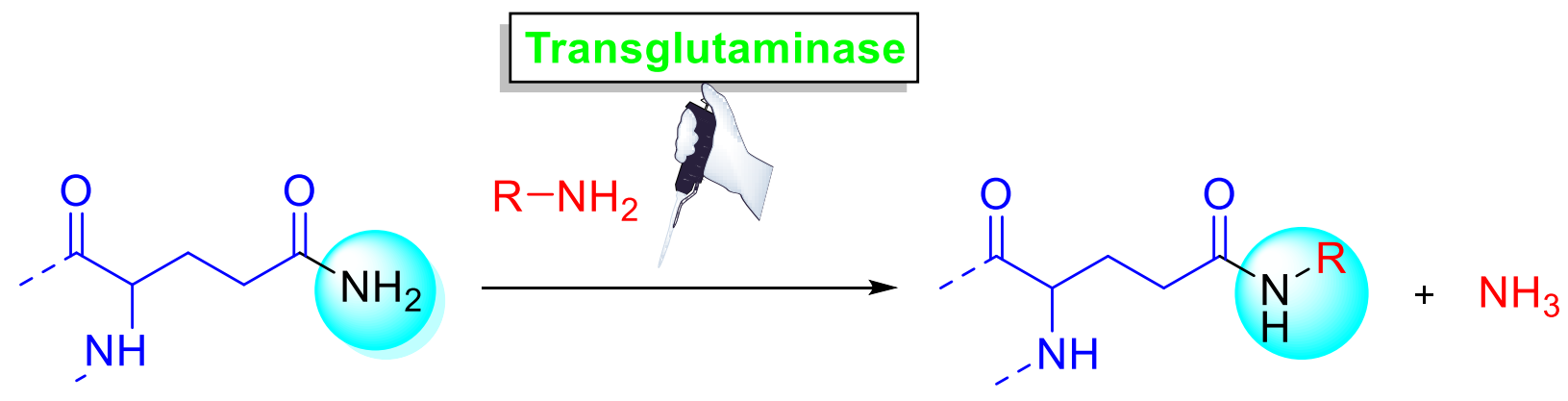

Fig. 1 Mechanism of the enzymatic reaction mediated by transglutaminase.

\section{Tyrosinase}


Likewise transglutaminases, tyrosinases are also known as phenoloxidase and monophenol monooxygenase, and catalyze macromolecular network formation without co-factors (39). Tyrosinase is a copper-containing enzyme that catalyzes phenols oxidation into activated quinones in the presence of $\mathrm{O}_{2}$, such as in dopamine and tyrosine residues (39). Activated quinones can react with an amino group or hydroxyl group, mostly via a michael-type addition reaction (Fig. 2) (40). Tyrosinases can be found in plants and animals and act in melanin formation, browning of food, and also cuticle hardening in insects (41). In most plants and animals, tyrosinases have rather a wide substrate specificity. Differently, substrate specificity is restricted to the L-form of tyrosine or DOPA in mammalian tyrosinases $(41,42)$. Chen et al. compared gels of gelatin and chitosan formed upon crosslinking using tyrosinase or transglutaminase and the results showed that tyrosinase induced faster gelation (57). Nonetheless, the hydrogels catalyzed by tyrosinase were fabricated in the presence of chitosan and were mechanically weaker. Gels formed by using tyrosinase are mainly appropriate as a glue (43) and wound dressings or could be used for protein immobilization (44), because of their quick degradation. Other applications of tyrosinase include the crosslinking of tyrosine residues in fibroin, sericin, and silk, yielding protein-polysaccharide conjugates $(45,46)$. Mishra et al used tyrosinase to provide enzymatically crosslinked carboxymethyl-chitosan/gelatin/nanohydroxyapatite injectable gels at $37^{\circ} \mathrm{C}$ for in situ bone tissue engineering application (47). These hydrogels showed potential for biomedical applications because of their exclusive mechanical properties, adhesiveness, and non-toxicity (12). 


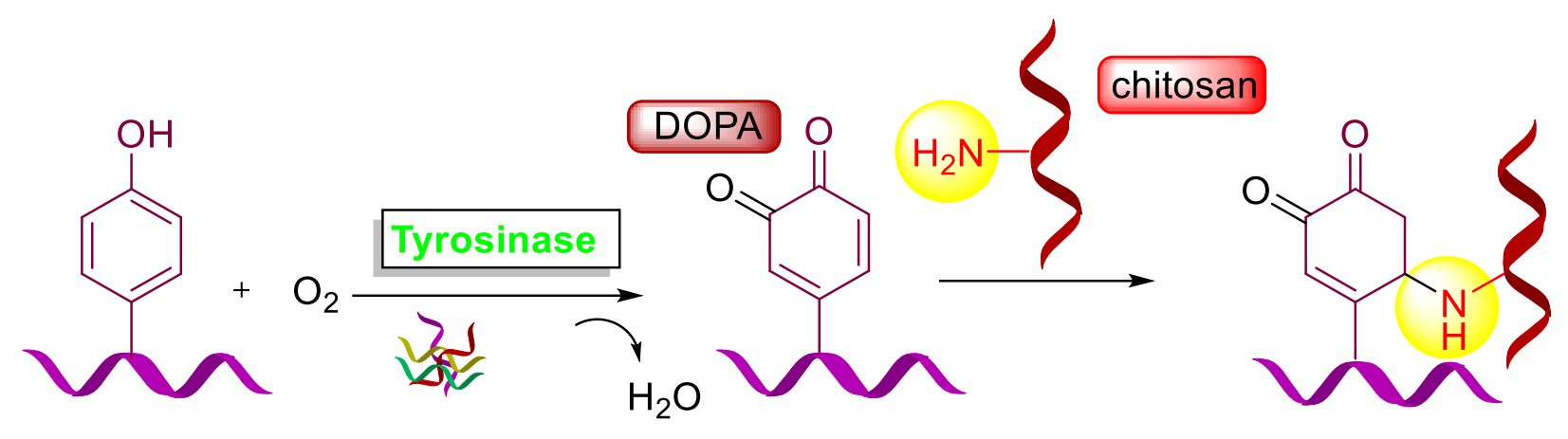

Fig. 2 Mechanism of the enzymatic reaction mediated by tyrosinase. Polymers conjugated with with phenol $(\mathrm{Ph})$ moieties such as tyramine, phenylalanine, tyrosine, hydroxyphenyl propionic acid, and 4hydroxyphenyl acetic acid in presence of oxygen and following amin groups of complementary polymer such as chitosan proceeded hydrogelation.

\section{Phosphopantetheinyl transferase}

Phosphopantetheinyl transferase is a small $(16.2 \mathrm{kDa})$ enzyme that employs to catalyze covalent cross-linking of many polymers in high efficacy. Therefore, it is different from transglutaminases, which have inadequate recombinant production and are higher in natuare. Transferases, which are expressed generally in the cytosolic compartment in a wide range of tissues, both in yeast and animal cells, include large multifunctional polypeptides that contain all of the catalytic components essential for the synthesis of long-chain fatty acids (48). The main mechanism of transferase catalysis to create synthetic hydrogels occurs by transfer of a phosphopantetheine prosthetic group of coenzyme in A-functionalized PEG macromers to a serine residue of engineered carrier proteins (Fig. 3). Phosphopantetheinyl transferase was used by Mosiewicz et al. to create hydrogels (49). Hybrid hydrogels were constructed by mixing the precursors of 8-arm-PEG-coenzyme A at $37^{\circ} \mathrm{C}$ and in the presence of $\mathrm{Mg}^{2+}$ and neutral $\mathrm{pH}$. The gelation was rather slow and completed in nearly $15 \mathrm{~min}$. The hydrogel reached an elastic 
modulus rate of $2.3 \mathrm{kPa}$. With this technique, selective covalent transferase-catalyzed hydrogels can be formed and modified with bioactive peptide ligands specifically the integrin receptor binding motifs, such as RGDs (Arg-Gly-Asp), which enable cell attachment and spreading (50). This type of reaction is greatly attractive for cell biology and tissue engineering applications.

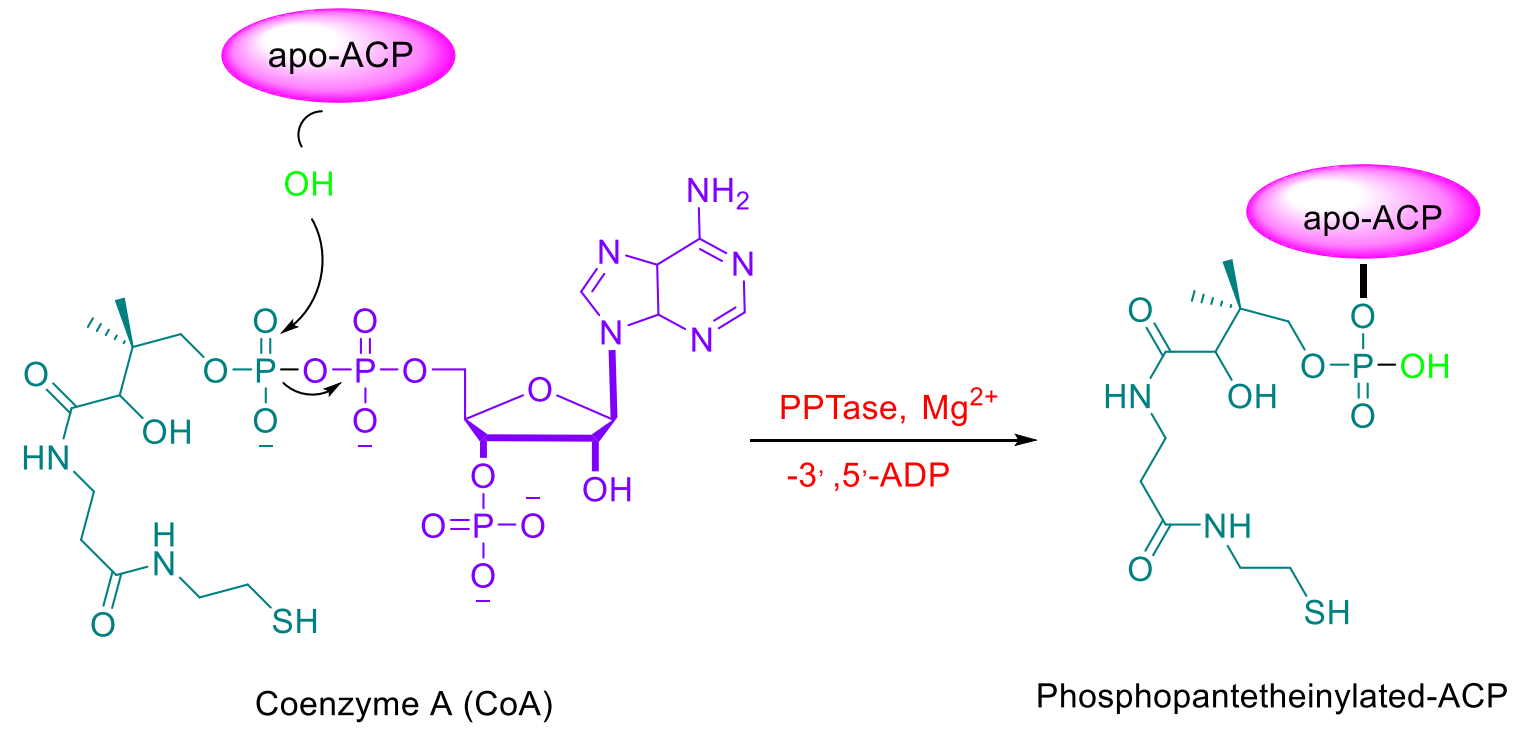

Fig. 3 Mechanism of lysyl phosphopantetheinyl transferase mediated reaction (49).

\section{Sortase A (SrtA)}

Sortase A (SrtA) categorizes among of a group of transpeptidases molecules with exceedingly specific activity for cross-linking which extracting from gram-positive bacteria. In this reaction, by cleavage of the bond between threonine and glycine in a $c$-terminal LPXTG recognition motif which proceed to form a thioester through conjugation of the amino group and carboxyl group from N-terminal glycine of complementary groups (51). Variaty of de novo designed peptides have been studied as feasible SrtA molecules $(19,52)$. Conjugation of human epidermal growth factor fused with a small soluble oligoglycine substrate, GGG motif (GGG-EGF) to poly 
(ethylene glycol) (PEG) hydrogels perfomed via sortase comprising LPRTG substrate. Increase of LPRTG in the hydrogel or GGG-EGF resulted raise of total tethered EGF. Results showed stimulation of DNA synthesis in human cells leads to activation of sortase-tethered EGF. The ease, and reversible sortase-mediated ligation and cleavage reactions demonesrated that as an desired methodology for adjustment of hydrogels (53).

\section{Lysyl oxidase and plasma amine oxidase}

Lysyl oxidase is one of important element in the constitution and regeneration of the original ECM. In the ECM in presence of lysyl oxidase, enzymatic reaction initirate through oxidation of primary amine of lysines to an aldehyde and the created reactive aldehydes spontaneously react with another amine to form a Schiff base or undergo an aldol condensation with another aldehyde (Fig. 4) (54). In fact, lysyl oxidase is acted to proceed covalent cross-linkage among the elastin and collagen fibrous derivatives and make them stable structure in ECM. Therefore, lysyl oxidase is resposible in the pattern formation of tissue, morphogenesis and repair ability of various connective tissues, comprising skeleton, cardiovascular, and respiratory tissues (55). Besides, plasma amine oxidase (PAO) is known as semicarbazide-sensitive amine oxidase which acts oxidation of primary amines, and it takes a crucial benefit of being accessible (54). Both above mentioned enzymes can be applied as a crosslinkers to develop biomaterial and tissue mechanical properties as wll as upregulation of ECM formation and tissue regeneration $(56,57)$. The lysyl oxidase was used by Bakota et al. to fabricate self anssembled nanofibrous from multi-domain peptides which proceed oxidative crosslinking of lysine residues. The most interesting feature of these hydrogels created by lysyl oxidase was their desirable mechincal properties including mechanical strength and handling of the hydrogel, as it becomes more 
robust with time rather than less so. This characteristic leads to a persistent upregulation in mechanical properties of networks made of rich lysine biopolymers. Furthermore, serum is contained lysyl oxidase. Therefore, in serum supplimented media, we can proceed crosslinking of lysine-containing polymers spontaneously without adding exogenous enzyme. Production of ECM by cells incorporated in the hydrogels enhanced by this enzyme. In summary, the lysyl oxidase have shown significance for a variety of applications including cell delivery, drug delivery and as scaffolds for tissue regeneration using multi-domain peptide hydrogels $(58,59)$. Besides, the inherent mechanical properties of tissue engineered constructs could be enhanced using lysyl oxidase by extention of culture time whereas facilites hydrogel integration with original tissue via covalent bond formation among lysine-rich molecules present in hydrogel and amines in tissue ECM.

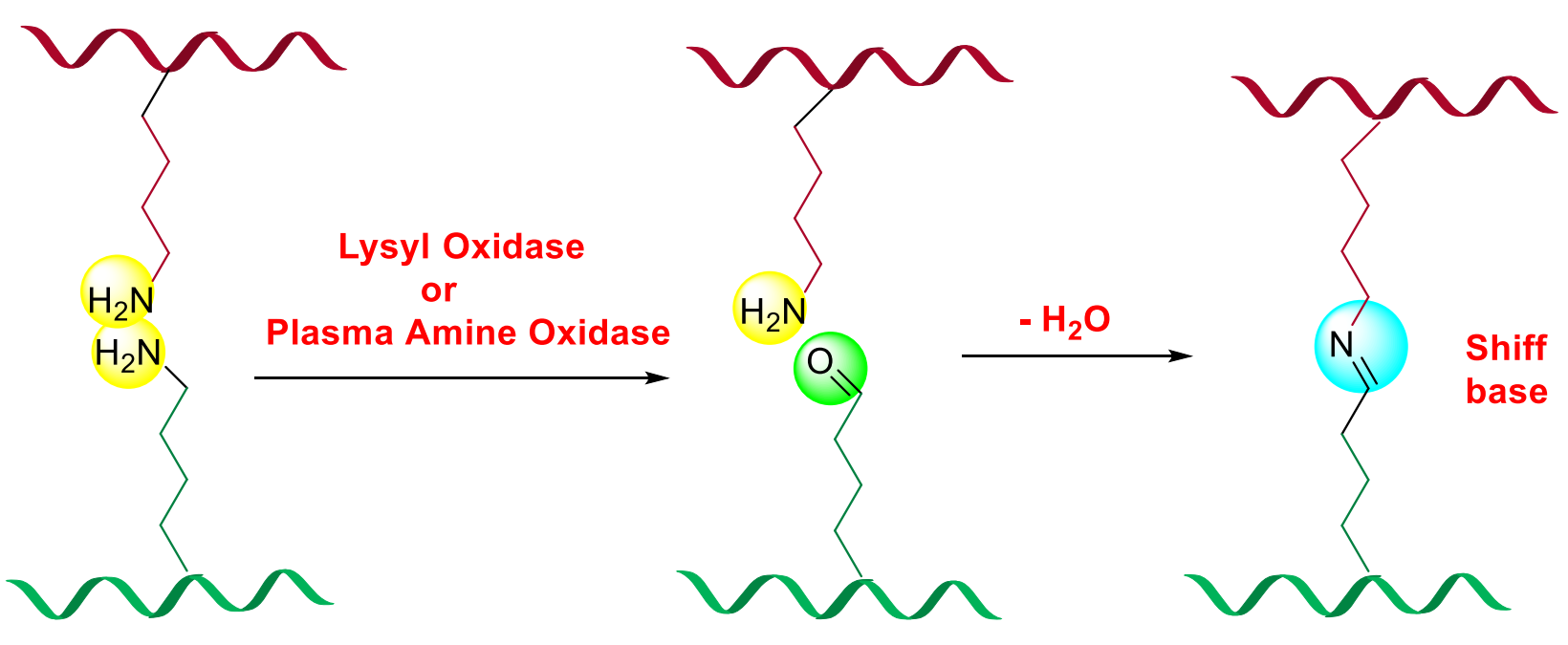

Fig. 4 Mechanism of lysyl oxidase or plasma amine oxidase-mediated reaction in fabrication of hydrogels (54). 


\section{phosphatase/ kinase derivatives}

Enzyme catalyzed or -regulated formation of hydrogels from small peptide derivatives can proceed through alteration of the amphiphilicity of phosphatase or kinase derivatives such as phosphatases, $\beta$-lactamase, thermolysin or phosphatase/kinase for instance, kinase or dephosphorylation interaction by a phosphatase. This alteration can, consequently, activate the physical interactions and self-assembly of the amphiphilic peptide moieties in hydrogel precursor solution, eventually leading hydrogelation, as shown in Fig. 5 (60, 61). These small peptides which mostly possessed bioactive or organic molecules can endure the addition of extra bioactivesubstrates. For instances, Phosphatase mediated the exclusion of phosphate moities fron peptide, resulting hydrophobicity of substates which may self-assemble into fibous network by noncovalent midiations (for instance, charge interactions, p-p interactions, hydrogen bonding) that makes hydrogelation possible (62). The amphiphilicity of peptide reformed by alteration of peptide instead of breaking the covalent linkages between the phosphate group and the peptide using thermolysin. In detail, thermolysin mediates to form bonds between peptides by reverse hydrolysis. This enzyme can be used to combine two distinct peptide derivatives, reducing the solubility of one of the peptides. This blocking peptide can then self-assemble into a hydrogel by hydrophobic interactions. Thermolysin prefers aromatic, hydrophobic residues on the amino side of the peptide bond. This system was presented by Toledano et al. with potential applications in the construction of nanofibrous hydrogel scaffolds for cell culture. The $\beta$-Lactamases and esterases are other enzymes that can be used as catalysts for molecular self-assembly (63). 


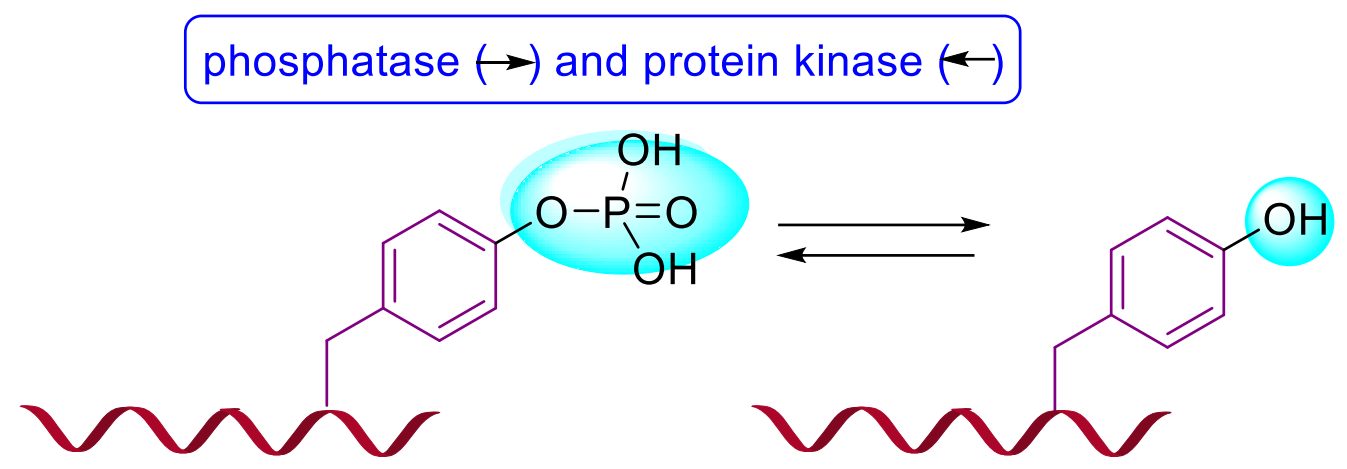

Alkaline phosphatase

$\beta$-lactamases

$\mathrm{R}_{\mathrm{COONa}}^{-\mathrm{SH}}=\mathrm{O}_{\mathrm{COONa}}^{\mathrm{N}} \longrightarrow \mathrm{R}_{\mathrm{O}}^{-\mathrm{S}}$

thermolysin

(O)<smiles>[R]COC(=O)NC1Cc2ccc(O)cc2CC(NC(=O)C(Cc2ccccc2)NC(Cc2ccccc2)C(=O)O)C1=O</smiles>

Fig. 5 Mechanism of the supermolecular hydrogel formation proceed different enzymes such as phosphatase/kinase, phosphatase, thermolysin, and b-lactamase (61). 
Both enzymes are involved in the hydrogel formation. The $\beta$-Lactamases are produced by Escherichia coli strains which are the reason of their resistance to $\beta$-lactam antibiotics, like streptomycin and penicillin. In this term, four-atom ring $\beta$-lactam molecular structure of antibiotics open by lactamase which this ring openting restict activation of antibacterial properties of the substate. In this reaction, the lactam ring of the hydrogel precursor compound opens by the lactamase and in following by release of hydrogelator, self-assembly convert precursors into hydrogel formation.Available lactamases in bacterial lysate enables them to act as a hydrogelator by converting the precursor molecule which leads hydrogel formation. These types of self-assembled hydrogels performed using $\beta$-lactamases or esterases can be used in bacterial analysises as well as trigger specific cellular cycle, since hydrogelation can take place within the cells $(64,65)$. Most of the enzymatic reactions in biological systems are irreversible and single enzyme hardly acts in reversible manner, which necessitate excessive modification of the peptide backbone of the crosslinked hydrogel to achieve reversible mechanism of reaction. Yang et al. synthesized a pentapeptidic hydrogelator forms hydrogels via the self-assembly using kinase/phosphatase which switch is used to control the phosphorylation and dephosphorylation of the hydrogelator and to regulate the formation of supramolecular hydrogels (66). This enzyme switch-regulated supramolecular hydrogels promises a new way to make and apply biomaterials because phosphorylation and dephosphorylation. These enzymes could regulate formation/dissociation of self-assembled hydrogel and the corresponding macroscopic transition in a supramolecular hydrogel. Using this enzymatic switch allows accurate control of biomaterial organization at a molecular level over time. hydrogel formation. These features of such enzymatic formed supramolecular hydrogels make them great promise for TE and other biomedical applications $(67,68)$. 


\section{Alkaline phosphatase(ALP)}

Alkaline phosphatases are especially remarkable source of the phosphatase to construct gels because of their participation in the mineralization of skeletal tissues (69). For this, self-assemble hydrogels fabricated by enzymatic dephosphorylation of N-fluorenylmethyloxycarbonyltyrosinephosphate (FMOC: fluorenylmethyloxycarbonyl, compound I, are utilized to form supramolecular network when mineralization of calcium phosphate (hydroxyapatite) is occoured

(Fig. 6). Dephosphorylation of compound I in water leads compound II that spontaneously assembles due to p-stacking of the fluorenyl end groups, which adopt a helical orientation because of super helical activities of the amino acid residues increasing from H-bonding interactions among the terminal tyrosine groups (69). Schnepp (69) fabricated materials by taking advantage of this property. These materials' viscoelasticity represents them appropriate substrates for application in rengerative medicine including tissue engineering, drug release, and wound healing purposes (12).

In addition, the core segment of yeast prion Sup35, a series of structurally related precursors have utilized for the alkaline phosphatase development of self-assembled hydrogels. Incorporation of an amyloid segment into a cytotoxic precursor could able to eliminate the cytotoxicity of the precursor solution and provides cytocompatible microenvironment (70). An enzyme-responsive hydrogel was designed by Toda et all by which elasticity could be changed by ALP in the cell culture. Consequently, the expression of Runx2, an osteogenic marker, was modified by ALP treatment for the deformed cells. This report demonstrated that the change of hydrogel's mechanical property could upregulate the expression of osteoblastic genes derived from human mesenchamal stem cells (MSCs) in vitro (71). 


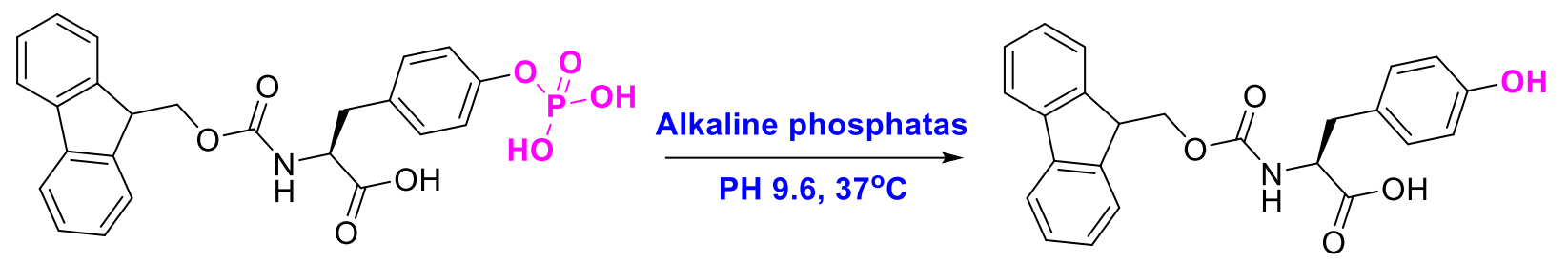

Fig. 6 Mechanism of hydrogel production by alkaline phosphatase-catalyzed dephosphorylation of FMOC-tyrosine-phosphate (I) which resulted formation of compound (II) with higher amphilicity and lower charge.

\section{Peroxidases}

Peroxidases are a broad family of enzymes that particularly catalyze the following reaction:

$$
2 \mathrm{RH}_{2}+\text { electron donor }(2 \mathrm{e}) \rightarrow 2 \mathrm{RH}^{\bullet}+2 \mathrm{H}_{2} \mathrm{O}
$$

Most of the peroxidases use hydrogen peroxide as a electron donor. This family consists of up to 42 isozymes, which makes it challenging to define in vivo functions $(8,72)$. The most frequently used peroxidases in hydrogel formations are horseradish peroxidase (HRP) and soybean peroxidase. The most important advantage of this enzyme in comparison to the previously described enzymes is quick gelation, which can happen in seconds (12). They are plant enzymes and are known as useful tools for biotechnology and biosciences(8, 72). Horseradish peroxidase is a single-chain $\beta$-type hemoprotein responsible for the catalysis of the conjugation of phenol and aniline derivatives in the presence of hydrogen peroxide $(11,73,74)$. Such groups are present, for instance, in tyramine, tyrosine, and 3-4-hydrophenyl propionic acid (75). In this reaction, the HRP rapidly combines with hydrogen peroxide, and the formed complex could oxidize hydroxyphenyl groups. In following the phenoxy radicals react through a radical coupling reaction generating covalent $\mathrm{C}-\mathrm{O}$ and $\mathrm{C}-\mathrm{C}$ bonds (Fig. 7). Soybean peroxidase is a potential substitute to the HRP, because of comparable mechanism of action and its superior 
stability. Human peroxidases have been widely studied, however usually, plant peroxidases have been utilized for enzymatic crosslinking to form hydrogels (76). This enzyme has advantages like non-cytotoxicity and the potential to crosslink in situ. An extensive range of natural and artificial polymers have been modified with tyramine or hydroxyphenyl propionic acid for the development of hydrogels by peroxidases. Examples of these hydrogels are hyaluronic acid (77, 78), gelatin $(74,79-81)$, dextran $(82)$, chitosan $(73,83,84)$, alginate $(85,86)$, xylans (87), carboxymethylcellulose (88), polyvinyl alcohol (PVA) (73), poly(ethylene oxide) (PEO) and poly(propylene oxide) (PPO) block copolymer (89), and poly (amido amines) (90). Polymerphenol molecules compared to thiol-modified polymers are not simply oxidized in the process of synthesis and are steady for extended time of maintenance. The HRP-mediated crosslinked reactions have been found significant attention and wide biomedical applications compared to other enzyme systems because of the easy possibility to regulate crosslinking and gelation rate by changing the amount of reactants including biopolymer, crosslinakble moieties, HRP and $\mathrm{H}_{2} \mathrm{O}_{2}(91)$.

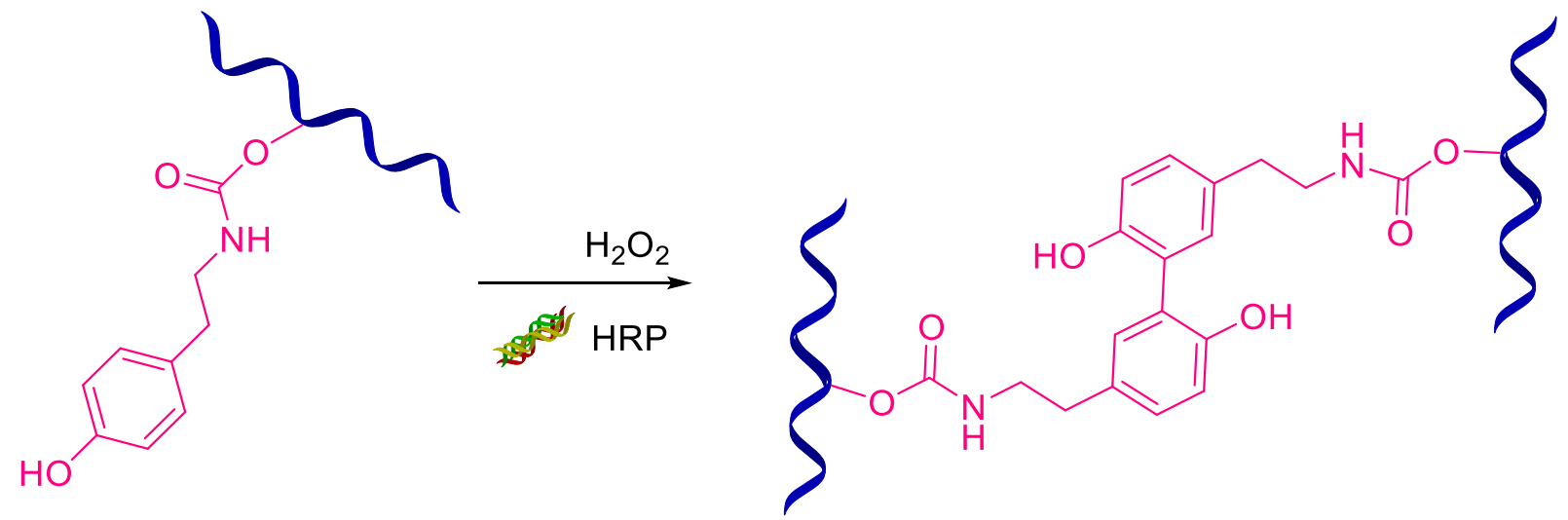

Fig. 7 Mechanism of the peroxidases reaction using hydrogen peroxide as an electron donor (14). 
Revealing the pathological and physiological manners attributed to extracellular reactive oxygen species (ROS) could facilitate hydrogelation without exogenous application of electron donor. Yang Liu et al. cytocompatible hydrogel membrane on indivitual cells produced via HRPmediated reaction and endogenous secretion ROS as an elector donor (92). Sakai et al. created cytocompatible hydrogel bulks performed on the surfaces of individual HRP anchored cells membrane by cross-linking of biopolymer compound mediated by HRP in aqueous solution. To hold the cross-linking development only on the cell surface, cells were soaked in a Ph substituted polymer (polymer-Ph) solution containing the HRP conjugated with a biocompatible anchor molecule (BAM-HRP) for cell membrane and HRP was made to anchore cell membrane. The hydrogel sheath of about $1 \mu \mathrm{m}$ thickness was attained by soaking the cells with the anchored $\mathrm{HRP}$ in an aqueous solution containing polymer-Ph and $\mathrm{H}_{2} \mathrm{O}_{2}$ within 10 min. The hydrogel sheaths could be created from a variety of polymer-Ph derivetives, such as derivatives of protein, polysaccharide, and synthetic polymer $(8,13)$. Cellular viability $(>90 \%)$ and subsequent normal growth after removal of the hydrogel sheath confirmed the cytocompatibility of the on-cell surface hydrogel sheath formation (93). Advances in encapsulation technology is a great promise for fundamental studies in cell biology and biomedical applications.

\section{HRP applications}

Darr et al. evaluated HA-Ph hydrogels that showed in vivo biocompatibility and stability to dissociation for injected hydrogel in subcutaneous tissue while maintaining the main of carboxyl groups with negative charge, essential for the contribution of the physio-mechanical properties of tissue (94). The HA-Ph molecules conjugated by HRP are promising candidate for tissue engineering and other biomedicine applications $(77,95)$. Dextran-Ph hydrogel combined with 
HA-Ph and heparin-Ph via HRP-mediated reaction mimic the the ECM of native cartilage (14, 96, 97). Similarly, Kim et al. described injectable $\mathrm{HA}-\mathrm{Ph}$ (98) as an efficient drug carrier for rheumatoid arthritis treatment. The supramolecular Ph-terminated PEG hydrogels are other polymer combinations using HRP to activate gelation $(75,89)$.

\section{Catalytic mechanism of peroxidase}

HRP is a heme-containing enzyme obtained from the root of horseradish (Armoracia rusticana). Heme is a complex between protoporphyrin and Fe(III). In HRP, the heme iron makes a coordinated bond by the nearest His170 residue in core region. There are various HRP isoenzymes, and the majority of them are C isoenzyme $(99,100)$. Mostly the catalytic reaction peroxidase involves the heme group and the amino acid residues in the protein core, such as His42 and Arg38. After binding of $\mathrm{H}_{2} \mathrm{O}_{2}$ to $\mathrm{Fe}(\mathrm{III})$ as the heme in its resting state, a proton transfer from the $\alpha$-oxygen of $\mathrm{H}_{2} \mathrm{O}_{2}$ to the His42 residue of HRP occurs. Afterward, the $\alpha$ oxygen forms a single bond with $\mathrm{Fe}(\mathrm{III})$, which results in a transient $\mathrm{Fe}(\mathrm{III})$-hydroperoxy intermediate that is defined as compound II (101). After that, the $\alpha$-oxygen forms a double bond with the heme iron, a procedure that is facilitated by the cleavage of the peroxide $\mathrm{O}-\mathrm{O}$ bond and an electron transfer from the porphyrin ring to the iron. This leads to a $\mathrm{Fe}(\mathrm{IV})=\mathrm{O}$ ferryl group and a porphyrin cation radical, which altogether is called Compound I. The residual -OH group of $\mathrm{H}_{2} \mathrm{O}_{2}$ receives the proton from the His42 residue to form water moelcule. Compound I proceeded two oxidation states above the resting state, and thus two successive electron transfers are necessary to reduce it back to the resting state. Here, the $\mathrm{Ph}$ moieties of polymer-Ph conjugates as the reducing substrate comes into action (Fig. 8). 
In the primary reduction step, a phenolic hydrogen atom is donated to compound I, and the electron of the hydrogen atom is transferred to the porphyrin cation radical. At the same time, the proton goes to the His42 residue. The first reduction results in the formation of the $\mathrm{Fe}(\mathrm{IV})=\mathrm{O}$ group and a phenolic radical. The second reduction step, which is a complex reaction involving the protonated His42 residue and an electron transfer from a phenol substrate, regenerates the $\mathrm{Fe}(\mathrm{III})$ and create a second phenolic radical with water as a leaving group. Thus, a catalytic cycle of HRP consumes one $\mathrm{H}_{2} \mathrm{O}_{2}$ molecule, converts two phenols into phenolic radicals and produces two water leaving groups. The phenol radicals pair with each other through either a $\mathrm{C}-\mathrm{C}$ linkage between the ortho-carbons of the aromatic ring or a $\mathrm{C}-\mathrm{O}$ linkage between the ortho carbon and the phenolic oxygen (102), and this leads to forming a cross-linkage among the polymer-Ph. Based on the catalytic mechanism, an increase in the $\mathrm{H}_{2} \mathrm{O}_{2}$ supply will generate more phenolic radicals, which in turn will form more phenol cross-linkages. In fact, when the concentrations of HRP and polymer-phenol conjugates are constant, increasing the $\mathrm{H}_{2} \mathrm{O}_{2}$ supply raises the shear modulus $\left(\mathrm{G}^{\prime}\right)$ and decreases the swelling percentage of the consequential hydrogels, representing an increase in the crosslinking density $(79,103)$. Beyond an optimum range of $\mathrm{H}_{2} \mathrm{O}_{2}$ concentration, a further increase in $\mathrm{H}_{2} \mathrm{O}_{2}$ causes the decrease $\mathrm{G}^{\prime}$ and this is probably due to a surplus amount of $\mathrm{H}_{2} \mathrm{O}_{2}$ reacting with $\mathrm{HRP}$ which consequently resulting in formation of two different types of catalytically inactive, including compounds III and IV (104). The compound III is a reversible intermediate which will gradually turnover native enzyme, leading to the restoration of catalytic activity. On the other hand, Compound IV is an irreversible compound which cannot recover its catalytic activity. HRP may also be inactivated via an attack on the protoporphyrin by phenoxyl radicals, which leads to heme demolition (105). As a consequence of HRP inactivation, the crosslinking reaction is inhibited. Therefore, the optimum concentration 
of $\mathrm{H}_{2} \mathrm{O}_{2}$ should be determined experimentally in order to avoid excessive use of $\mathrm{H}_{2} \mathrm{O}_{2}$. Anja Schmidt et al. suggested that an H2O2: HRP molar ratio of higher than 100 would lead to a reduction in $\mathrm{G}^{\prime}$, which corresponds to the reported value at which Compound IV is formed (104). The gelation rate of the HRP-mediated crosslinking reaction is greatly dependent on the concentration of $\operatorname{HRP}(79,103)$. It is anticipated that further enzymes would allow a faster rate of phenolic radical formation, conducting to a faster velocity of crosslinking. Hydrogels are produced ina range of time of a few seconds to several minutes, depending on the HRP concentration.

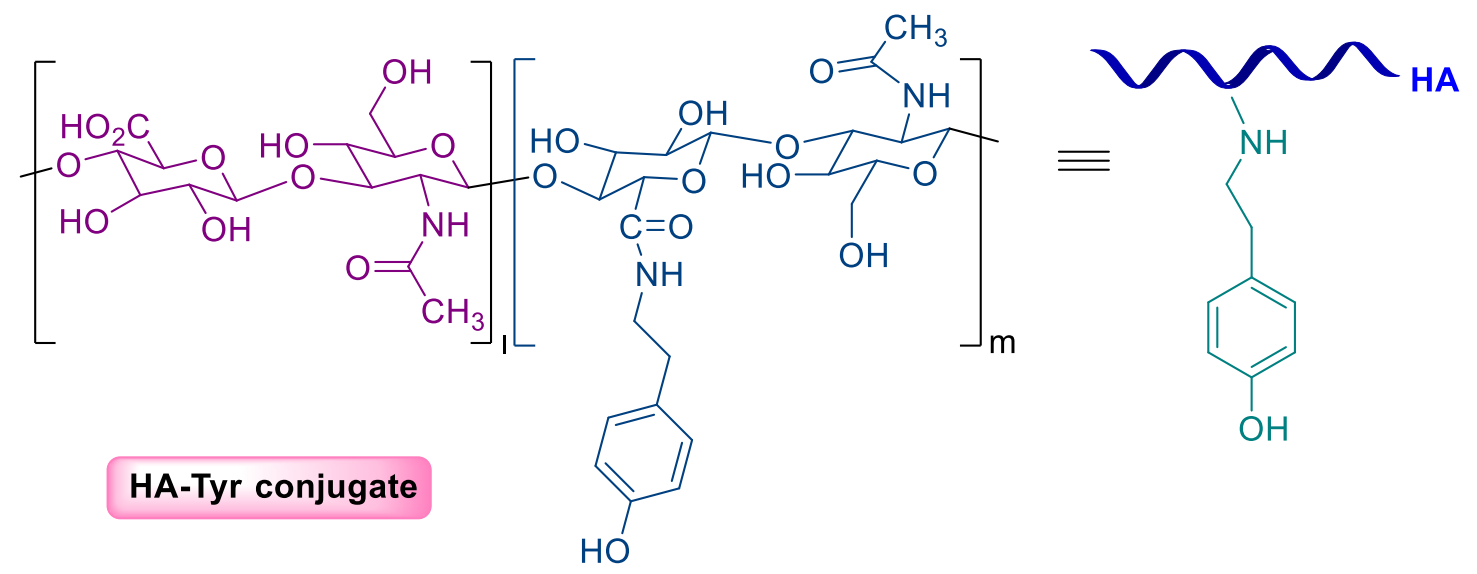




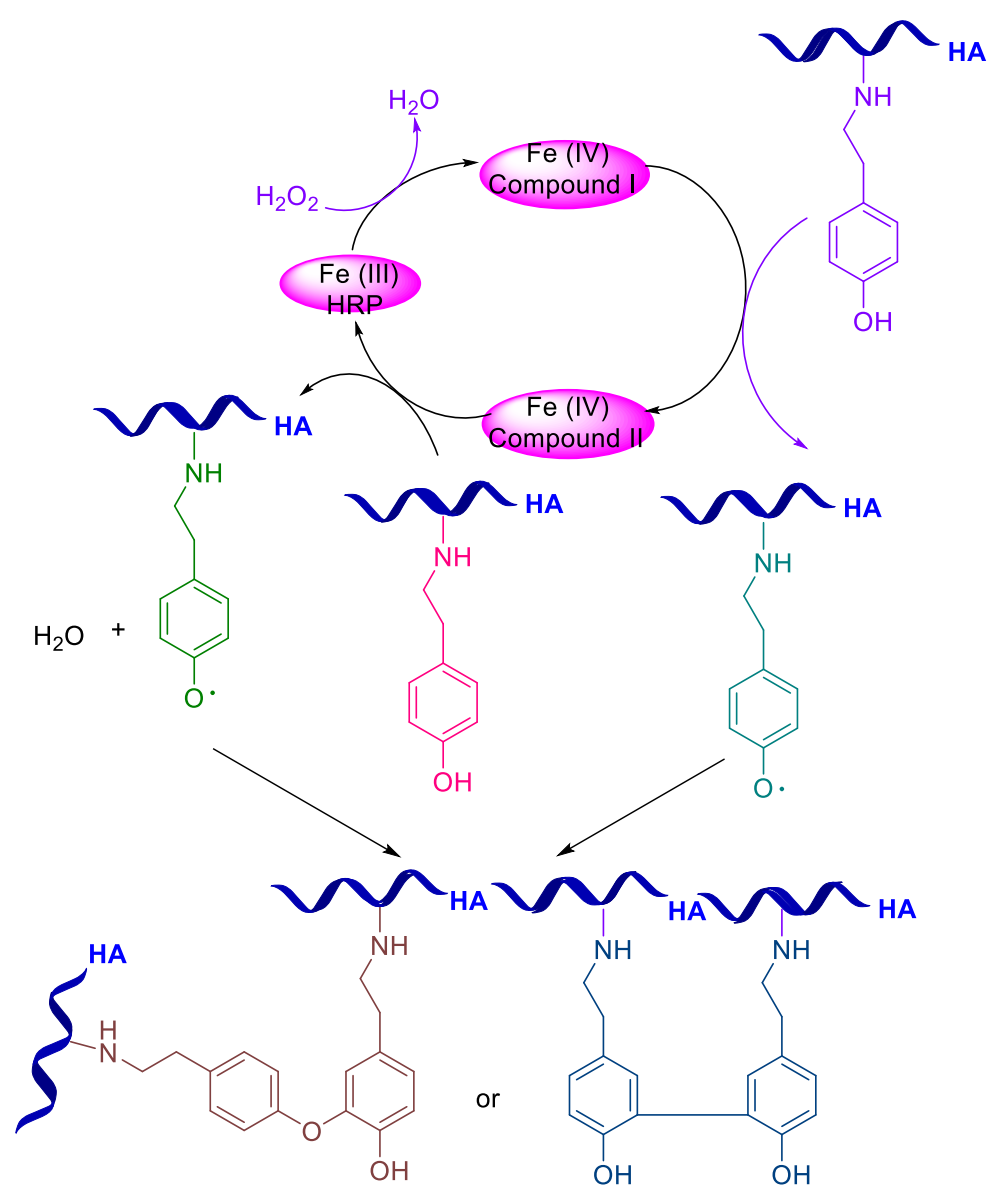

Fig. 8 Crosslinking mechanism of HA-Tyr conjugates by the HRP-mediated crosslinking reaction(106).

\section{Applications of hydrogels formed by enzymatic reactions}

\section{Drug Delivery}

In order to use hydrogels as injectable protein delivery systems, it is essential to adjust the gelation rate and crosslinking density of gel networks to avoid encapsulation inefficiencies like an abrupt leakage of gel precursors and protein drugs to the surrounding tissues, caused by slow gelation after injection (106). The crosslinking density of hydrogels is a crucial factor in leading their drug release properties (107). An increase in the degree of crosslinking causes a reduction in the porosity and permeability of gel networks. Therefore, the rate of drug release typically decreases $(108,109)$. The HRP catalyzed crosslinking method allows independent regulation of 
the gelation rate and crosslinking density through a variation of $\mathrm{HRP}$ and $\mathrm{H}_{2} \mathrm{O}_{2}$ concentrations $(108,109)$. This is very advantageous for in situ-forming hydrogels for the delivery of protein drugs and growth factors (95). An injectable hyaluronic acid-tyramine (HA-Tyr) hydrogel was formed using this system for protein drug delivery by van de Wetering $\mathrm{P}$ et al. (95). The release rate of $\alpha$-amylase and lysozyme could be regulated by manipulating the crosslinking density of HA-Tyr hydrogels. HA-Tyr hydrogels were applied for the in vivo delivery of interferon- $\alpha 2 \mathrm{a}$ (IFN) (110), which is an antineoplastic cytokine used in the treatment of various types of human cancers. The IFN-incorporated HA-Tyr hydrogels demonstrated greater antitumor efficiency compared to the IFN solution injected at the same dose. Improved anticancer result was related to the inhibition of tumor angiogenesis with the treatment of IFN-incorporated HA-Tyr hydrogels. Lutolf et al have design oligopeptide building blocks through dual enzyme-responsive poly(ethylene glycol) based hydrogel able to undergo formation and degradation in response to cell-secreted matrix metalloproteinases.

Paeonol as hydrophobic drug model release behaviour from poly(vinyl alcohol) (PVA)/silk fibroin hydrogels fabricated through the HRP crosslinking method were invistaged. The pheonol from the hydrogels showed an initial burst release and slow sustained release in longer period of time which proved these hydrogels are attractive candidates for drug delivery and engineering applications. Self-assembled heparin-pluronic (HP) nanogels encapsulating bFGF were dispersed in gelatin-poly(ethylene glycol)-tyramine (GPT) polymer solution and used as a protein drug carrier. The macro/nanogel composite hydrogels were produced by the HRP-catalyzed oxidative coupling of GPT conjugates $(111,112)$. The GPT/HP composite hydrogels presented a considerably higher density of urethral muscles nearby the urethral wall compared to the GPT hydrogels. Devolder et al. showed an improvement in protein release kinetics from composite 
hydrogel systems through the HRP-mediated crosslinking of pyrrole groups (113). An alginateg-pyrrole hydrogel including PLGA microspheres loaded with vascular endothelial growth factor (VEGF) was developed by the HRP-catalyzed crosslinking of pyrrole groups that were conjugated to an alginate backbone. In spite of a lower crosslinking density, the enzymatically crosslinked alginate-g-pyrrole hydrogels released VEGF in a more sustained manner than $\mathrm{Ca}^{2+}$ crosslinked alginate-g-pyrrole hydrogels. The bipyrrole moieties produced following the enzymatic crosslinking contributed to a more sustained VEGF release by increasing the affinity of the growth factor and the gel matrix. This characteristic was advantageous to enhancing neovascularization in vivo. The enzymatically crosslinked alginate-g-pyrrole hydrogels notably improved both the number and size of blood vessels at the injection site, as equated to the $\mathrm{Ca}^{2+}$ crosslinked hydrogels (91). Dehghan-Niri et al. represented injectable enzymatically crosslinked hydrogels based on Gum tragacanth (GT)-tyramine that were prepared by oxidative coupling reaction in the presence of $\mathrm{HRP}$ and $\mathrm{H}_{2} \mathrm{O}_{2}$. Incorporation of tyramine-conjugated gelatin (GtnTA) into the hydrogels reduced the hydrogel swelling degree and the burst release of BSA. The release of BSA and insulin from tragacanthin(TGA)-TA/Gtn-TA hydrogel showed that the release of insulin was faster due to its lower molecular size and weight. TGA-TA/Gtn-TA hydrogels can be a promising candidate for in situ-forming systems for delivery of therapeutic proteins(114).

\section{Tissue engineering and cell therapy}

The mechanical characteristics are critical in designing injectable hydrogels for tissue engineering not only to have sufficient durability under dynamic in vivo conditions, but also to provide encapsulated cells with an appropriate mechanical environment that leads to proper cell 
proliferation, differentiation, and tissue regeneration $(115,116)$. The mechanical property of hydrogels requires to be adjusted based on the mechanical microenvironment of the aimednative tissue. In this regard, the HRP-catalyzed crosslinking method is favorable because it offers advanced control over the mechanical strength of hydrogels through changing the $\mathrm{H} 2 \mathrm{O} 2$ concentrations (117). Wang et al. created gelatin-hydroxyphenyl propionic acid (Gtn-HPA) hydrogels as an injectable scaffold for tissue engineering $(116,118)$. The storage moduli $\left(\mathrm{G}^{\prime}\right)$ of Gtn-HPA hydrogels was readily adjusted from 280 to $12800 \mathrm{~Pa}$ through a variation of $\mathrm{H}_{2} \mathrm{O}_{2}$ concentrations. The hydrogel hardness resulted the focal adhesion, proliferation, and differentiation of human mesenchymal stem cells (hMSCs) cultured in 2D and 3D environments. The cells cultured in a softer hydrogel expressed much more neurogenic protein markers, compared to those cultured in a harder hydrogel. Lim et al. studied the influence of Gtn-HPA hydrogel matrices on the oxidative stress resistance, migration, and differentiation of adult neural stem cells (ANSCs) (119). The G' of Gtn-HPA hydrogels was adjusted (449-1717 Pa) to be similar to adult brain tissue. Remarkably, the ANSCs encapsulated in Gtn-HPA hydrogels demonstrated a greater resistance to $\mathrm{H}_{2} \mathrm{O}_{2}$-induced oxidative stress, whereas those encapsulated in collagen and alginate hydrogels had harsh necrosis (120). This property would be beneficial for the regeneration of injured brain tissue since ANSCs transplanted at damaged sites in the brain have poorly survived probability because of exposure to oxidative stress and other uncongenial factors (121). The Gtn-HPA hydrogels displayed an improved differentiation of ANSCs towards neuronal lineage, compared to polyornithine/laminin coated polystyrene substrates in mixed conditions for both neuronal and astrocytic differentiation. Gtn-HPA hydrogels were used for cartilage repair in an in vivo osteochondral defect model (122). GtnHPA hydrogels with different hardness $\left(\mathrm{G}^{\prime}=570,1000\right.$, and $\left.2750 \mathrm{~Pa}\right)$ were mixed with rabbit 
chondrocytes, and injected into full-thickness osteochondral defects of the femur. The results suggested that the higher hardness of Gtn-HPA hydrogels stimulated the biosynthesis of type II collagen and sulfated glycosaminoglycans (sGAG) from the encapsulated chondrocytes and consequently promoted cartilage tissue repair in vivo. In addition to Gtn-HPA hydrogels, various polymerphenol hydrogels have been broadly used for tissue engineering applications. The HATyr hydrogels were investigated as biomimetic matrices for the chondrogenic differentiation of caprine MSCs (123). Recombinant human lactoferrin (rhLF) hydrogels were also created for bone tissue engineering due to the anti-apoptotic and osteogenic activity of rhLF towards preosteoblast cells (124). Jin et al. demonstrated injectable dextran-tyramine hydrogels as 3D scaffolds for cartilage regeneration $(14,91)$. Chondrocytes incorporated in the hydrogels kept their phenotype and formed a cartilaginous-specific matrix following in vitro culture. Teixeira et al. represented that the HRP-mediated crosslinking reaction induced strong adhesion between cartilage and dextran tyramine hydrogels (125). Histological and morphological assay of the cartilage-hydrogel interface indicated that dextran-tyramine conjugates were chemically bound to collagen molecules present in the cartilage ECM by a tyramine-tyrosine linkage. The incorporation of heparin-tyramine conjugates made the homing of human chondrocytes and chondrocyte progenitor cells easier using the dextran-tyramine hydrogels. The cell-attracting effect was probably related to the high affinity of heparin with growth factors and cytokines (91, 111). Kuo et al prepared autologous extracellular matrix scaffolds, murine collagen-Ph hydrogels, and demonstrated the appropriateness of injectable horseradish peroxidase crosslinked collagen-Ph hydrogels for human progenitor cell-based development of 3D vascular networks in vitro and in vivo. They also confirmed that the biodegradability, swelling properties and stiffness of the collagen-Ph hydrogels regulated by changing the amount of crosslinking 
could be used to adjust not only the extent of the vascular network but also adipose and mineralized tissue configuration in vivo. They emphasized the significance of ECM in providing proper signals for endothelial-mediated vascular development, which is important for the initial stages of organogenesis to engineer cell based 3D tissue constructs (126). Sakai et al. reported the first method of cell-selective encapsulation in hydrogel sheaths. Cell selectivity was accomplished through an antigen-antibody reaction. Biocompatible encapsulation was achieved throughout a cross-linking reaction, catalyzed by an HRP-conjugated antibody immobilized on the cell surface. This method was achieved by using two different systems including using primary antibody conjugated with HRP, and using a primary antibody with a secondary antibody conjugated with HRP. This method has great potential of cell-to-cell communication, regenerative medicine, and cell therapies (127). Morelli et al. reported the conversion of ulvan, a sulfated polysaccharide of algal origin, into an in situ gelling material suitable for biomedical applications. Ulvan was successfully modified with tyramine units in order to be susceptible to crosslinking reactions catalyzed by horseradish peroxidase enzymatic action in the presence of $\mathrm{H}_{2} \mathrm{O}_{2}$. The amount of used enzyme and $\mathrm{H}_{2} \mathrm{O}_{2}$ were optimized in order to induce times of gelation appropriate for the development of injectable hydrogels. Also, the preliminary biological investigations indicate the suitability of the enzymatically crosslinked ulvan hydrogels to function as a vehicle for viable cells supporting the possibility of their application as injectable cell delivery systems (128). Khanmohammadi et al. introduced the preparation of cell-enclosing hyaluronic acid (HA) microparticles with either solid or liquid cores through cell-friendly horseradish peroxidase (HRP)-catalyzed hydrogelation using a microfluidic system. The spherical tissues covered with a heterogeneous cell layer would be useful for biomedical and pharmaceutical applications (129-131). Liu et al. assembled small tissue enclosing hydrogel 
microcapsules (about $200 \mu \mathrm{m}$ in diameter) and a single hydrogel fiber, both covered with human vascular endothelial cells in a collagen gel. The fiber and microcapsules were made from gelatin and alginate derivatives, and had cell adhesive surfaces. The endothelial cells on the hydrogel constructs sprouted and spontaneously produced a network linking the hydrogel constructs together in the collagen gel. Alginate-based hydrogel constructs degraded by alginate lyase and perfusable vascular network-like structure was formed. Confirmation was done by introducing solution including tracer particles of about $3 \mu \mathrm{m}$ in diameter into the lumen model by the alginate hydrogel fiber. The introduced solution moved into the created capillary branches and distributed to the individual spherical tissues. The method is a great promise to develop the technique for constructing an internal perfusable vascular network for the fabrication of dense 3D tissues in vitro for biomedical applications (132). Tomita et al. produced HRP fabricated hyaluronan (HA) microcapsules feasible for use in the cryopreservation of a small number of sperms for clinical applications (133).

\section{Wound healing}

Tissue adhesives are useful for sealing defects in tissues, stopping bleeding, and promoting wound healing (134). Fibrin glue and cyanoacrylates are two clinically available adhesives. Fibrin glue has been regularly used as an adjunct to hemostasis in a surgical procedure. Nevertheless, fibrin glue has been used only to stop low-pressure bleeding because of its comparatively low adhesive power (135). Cyanoacrylates revealed comparatively strong adhesion to tissues but released toxic substances like cyanoacetate and formaldehyde during degradation (136). The HRP-catalyzed crosslinking technique provided a new prospect because this technique enabled fast gelation ranging from seconds to a few minutes in mild conditions. 
Lih et al. created injectable chitosan poly (ethylene glycol)-tyramine (CPT) hydrogels as fast biocompatible and durable tissue adhesives (137). Tyramine-modified PEG chains were engrafted into a chitosan backbone to raise its solubility at physiological $\mathrm{pH}$. Upon application, CPT hydrogels were produced in less than 5 seconds throughout the HRP-catalyzed coupling of tyramine moieties. These hydrogels provided great tissue adhesion with an adhesive power of almost 20 times higher than that of fibrin glue. CPT hydrogels rapidly stopped the bleeding from injured livers through the combined effect of the adhesiveness of these hydrogels and the hemostatic characteristic of chitosan (138). CPT hydrogels efficiently closed the skin injuries and showed greater wound healing property in comparison to suture, fibrin glue, and cyanoacrylate. Tran et al. described rutin-conjugated CPT hydrogels for dermal wound healing (139). Rutin is a flavonol glycoside that exhibits antioxidative, cytoprotective, and wound healing properties (140). Rutin was conjugated to a chitosan backbone of CPT polymer by an ester linkage. In vitro study revealed that the conjugated rutin was gradually released from CPT hydrogels through hydrolysis of the ester linkage. The rutin-conjugated hydrogels considerably enhanced wound healing compared to the hydrogels without rutin. These results imply that the combination of bioactive molecules and injectable hydrogels can produce a novel type of tissue adhesives with improved hemostatic and wound healing properties (91). Zavada et al. reported more developed enzyme-mediated hydrogel for wound dressing, fabricated from a phenol functional poly(vinyl alcohol) and the glucose oxidase (GOx)/HRP combination (141). In order to proceed polymerization, this method needed both glucose and oxygen. In vivo application, the mixture of polymer, HRP and GOx would only solidify once it gets in touch with a glucose and oxygen supply which is avaialbe in blood flow. Therefore, the constructed hydrogel could be practical when the formulation is utilized for a bleeding wound. Gelation times of less than $10 \mathrm{~s}$ 
were readily achievable and the hydrogels demonstrated no marks of bio-incompatibility from any of the residual enzymes. Another advancement would be containing glucose in the formulation and using molecular oxygen, everywhere in the atmosphere, as the environmentallyborne stimulus. This approach has been represented for GOx/HRP-mediated thiol-ene polymerization (142). A formulation of thiol-ene monomers with glucose, GOx and HRP could be useful via spray, where the promptly accessible surfaces of atomized droplets would allow quick oxygen diffusion, leading to the initiation of the polymerization. An advantage of this method over the formulations based on blood glucose is that the risk of left unpolymerized material is reduced. In addition to the GOx/HRP pair, there are probably other enzymatic systems of inducing oxygen-mediated in situ polymerization, particularly laccase as it is able to create radicals straight from molecular oxygen (143). Sakai et al. fabricated an on-tissue surface hyaluronic acid-based hydrogel by administration of a pre-hydrogel aqueous solution with the purpose of preventing postoperative peritoneal adhesion which is a serious surgical complication. The hydrogelation is initiated when hydrogel precursor solution contact with the body fluid containing glucose on tissue surfaces, and it is accomplished in 5s. In hydrogelation process, a hyaluronic acid derivative possessing phenolic hydroxyl moieties cross-link by a cascade reaction of GOx and HRP. A significant reduction in peritoneal adhesions was found in animal models (144).

\section{Safety of HRP hydrogelating reactions}

One of the worries related to the enzyme mediated crosslinking reaction is the maintenance of the enzyme in the hydrogel. Because HRP is a plant-derived protein, it may provoke an immunological response when inserted into the human body. Researchers have revealed that the 
protein core, as well as the N-glycans of HRP, could evoke the production of antibodies in rodents (145). Even though the rodents were immunized under the stimulation of Freund's adjuvants to intensify the immune response, the immunogenicity of HRP in the human body, especially with frequent exposures, cannot be ignored. Therefore, the safety of HRP in humans must be confirmed before the clinical application of hydrogel formulations containing HRP. On the other hand, if a human peroxidase, which can competently catalyze the oxidative coupling of phenols, is recognized, then it can act as a safer alternative to HRP (12). But the high price of human proteins and the deficiency of the activity of the human peroxidase in catalyzing the crosslinking of polymer-phenol conjugates still hinder their application. For example, human myeloperoxidase has been revealed to catalyze the oxidative crosslinking of free tyrosine residues in the presence of $\mathrm{H}_{2} \mathrm{O}_{2}$. Still, it wasn't able to crosslink tyrosine-containing polypeptides because of probable steric interference towards larger substrates (146). consequently, it stays to be studied whether human peroxidases like myeloperoxidase are able to catalyze the crosslinking of polymer-phenol conjugates and the creation of hydrogels.

\section{Hematin-based HRP biomimetic}

Catalytically useful HRP mimetics are prospective options that can avoid the safety issues of HRP. One example is hematin, which is a complex between protoporphyrin IX and ferric ion $\left(\mathrm{Fe}^{3+}\right)$, with a hydroxyl group adjacent to the iron atom. Like HRP, hematin is initially oxidized by $\mathrm{H}_{2} \mathrm{O}_{2}$ and subsequently experiences a range of electron transfers with the substrates previous to finally returning to its original state (147). Sakai et al. reported that hematin could catalyze the crosslinking of gelatin-phenol and carboxymethyl cellulose-phenol conjugates, producing hydrogels in situ (148). Despite that the catalytic activity of hematin is lower than HRP in terms 
of per unit weight of the catalyst, the most important advantage of utilizing hematin as a substitute catalyst in hydrogel construction is its safety and lower potential side effects in human $(149,150)$. However, one disadvantage of hematin is its low solubility in water. The dissolution of hematin demands alkaline solution before neutralization, and even with this dissolution protocol, the constitution of hematin aggregates was still detected (150). To enhance the solubility of hematin, pegylated hematin (151) and chitosan-g-hematin (150) have been combined, which facilitated the gelation of catechol-containing polymers. The potential cytotoxicity of hematin at high concentrations is another issue (152). Even though 95\% cell viability was seen when incorporated in gelatin-phenol hydrogels crosslinked by $0.05 \%(\mathrm{w} / \mathrm{v})$ hematin and $4 \mathrm{mM} \mathrm{H}_{2} \mathrm{O}_{2}$ (148), more detailed studies are needed to establish the effect of hematin for tissue engineering applications.

\section{Enzyme/catalyst/ -free hydrogels}

Hematin has also been immobilized on the inner surface of passing channel including needle surface to produce catalyst-free hydrogels (152). To immobilize hematin, primary amine was inserted to the inner surface of a syringe by coating with poly(dopamine) (pDA), which next reacted with the carboxyl group of hematin throughout NHS/EDC chemistry. Hydrogels were effectively created by passing a solution of catechol-tethered chitosan and $\mathrm{H}_{2} \mathrm{O}_{2}$ through the syringe. The oxidation of catechols occurred in contact with the immobilized hematin, creating quinone radicals which react with catechols or amine groups of chitosan to construct cross linkages. It was revealed that the $\mathrm{G}^{\prime}$ being increased $1 \mathrm{~h}$ after the gel precursors were rinsed out of the syringe, representing that when the catechols oxidized during contact with hematin, they stayed active for crosslinking formation. Although this method is performed widely for catechol- 
containing polymers, still more experiments are needed for the formation of tyramine-based hydrogels. Bae et al. represented a new perspective to producing enzyme-free hydrogels using ferromagnetic microbeads conjugated with HRP (153). In this system, a combination of gelatinpoly(ethylene glycol)-tyramine and $\mathrm{H}_{2} \mathrm{O}_{2}$ were loaded into a syringe filled with HRP-beads. As the mixture was moved through and rinsed out of the syringe, the tyramine moieties were oxidized whereas the HRP-beads remained. It was determined that the contact time regulated the hardness of the consequential hydrogel. Increasing the contact time from 5 to $30 \mathrm{~s}$ raised the storage modulus from 10 to $2200 \mathrm{~Pa}$. The reason is that the HRP-mediated oxidative reaction could just be happened while the polymer and $\mathrm{H}_{2} \mathrm{O}_{2}$ mixture were in interaction with the HRPbeads. Therefore, increasing the contact time would cause the creation of more tyramine radicals, which could contribute to the crosslinking reaction. Although this system forms hydrogels that are free of HRP, injectability may become an issue if stiffer hydrogels are produced during longer contact time with the HRP-beads in the syringe. Interstingly, catalyst/enzyme-free hydrogels prospect the most worthwhile alternative for biomedical applications of injectable hydrogels crosslinked by phenol coupling.

\section{Cytotoxicity of $\mathrm{H}_{2} \mathrm{O}_{2}$}

The utilizing $\mathrm{H}_{2} \mathrm{O}_{2}$ is a further concern related to the enzyme mediated crosslinking reactions. In vitro models have revealed that low concentrations of $\mathrm{H}_{2} \mathrm{O}_{2}$ (micromolar) in the culture medium cease the cell growth whereas high concentrations (micro to millimolar) cause apoptosis and necrosis (154). The $\mathrm{H}_{2} \mathrm{O}_{2}$-induced cytotoxicity also relies on the incubation time. In one experiment using C6 glioma cells, it was dosclosed that the average cytotoxic concentration of $\mathrm{H}_{2} \mathrm{O}_{2}$ was reduced from $500-30 \mu \mathrm{M}$ as the incubation time was raised from 1 to $24 \mathrm{~h}$ (155). This 
dependance indicates that the cytotoxic consequences of $\mathrm{H}_{2} \mathrm{O}_{2}$ could be less significant if $\mathrm{H}_{2} \mathrm{O}_{2}$ is quickly used by the HRP mediated oxidative reaction $(119,123,156)$. Also, it was shown that the transient contact to $\mathrm{H}_{2} \mathrm{O}_{2}$ through the crosslinking procedure could help rat aNSCs to endure oxidative stress, showing a higher survival rate in comparison to the cells without pre-exposure when exposed to the second addition of $\mathrm{H}_{2} \mathrm{O}_{2}$ (119). Moreover, because HRP inactivation may result in slow or not complete use of $\mathrm{H}_{2} \mathrm{O}_{2}$, which can make the residual to cause toxicity to the embedded cells, it is essential to avoid using higher concentraions of $\mathrm{H}_{2} \mathrm{O}_{2}$ in order to avoid HRP inactivation. It is also suggested to combine the polymer-phenol conjugates, HRP, and cells before the addition of $\mathrm{H}_{2} \mathrm{O}_{2}$ to lessen the exposure time of the cells to $\mathrm{H}_{2} \mathrm{O}_{2}$. Moreover, the HRP is composed cysteine residues and its thiol moites can oxidase whereas glucose is reduced disulfide bond to thiol moites. Therefore, the oxidation and in following reduction cycle of sulfate derivatives was proceeded hydrogelation of polymer-Ph and even could consider polymer- $\mathrm{Ph}$ hydrogelation in $\mathrm{H}_{2} \mathrm{O}_{2}$ exlude reaction with mixing polymer derivative with $\mathrm{HRP}$ in higher concentrations. These findings have shown that the HRP-mediated crosslinking reaction is an appropriate choice to form cell-laden hydrogels (91).

\section{HRP enzymatic reaction in 3D printing}

3D printing provides the possibility to simulate complex 3D tissues and biomedical products by precise deposition of gel precursors and cells through printing techniques, like microextrusion or inkjet printing (157). Rapid gelation rate, which facilitates the fabrication of 3D structures, is crucial for crosslinking reaction in bioprinting. HRP has suitable properties to use in this approach. Murphy et al. evaluated commercially available tyramine-substituted HA. Since the high viscosity of the gel precursor solution is another crucial issue in bioprinting they used 
compressed air to drive the gel precursors to the printing-head nozzle (158). Hu et al. revealed that cell-seeded hollow fibers could be fabricated through enzymatically crosslinking the GtnHPA hydrogel in solutions flowing laminarly inside a triple-orifice extruder (159). Different diameters of fibers could be formed by changing the input flow rate (160). Additionally, it is possible to create enzyme-free 3D tissue constructs by driving the gel precursors through HRPbeads or hematin-coated tubing before exiting from the printing-head nozzle. The printing of hydrogels crosslinked by the enzyme-mediated reactions like HRP has a great potential in tissue engineering and other biomedical applications.

\section{A-chymotrypsin}

A-chymotrypsin was found to promote the self-assembly of amino acid derivatives for the production of supramolecular hydrogels $(161,162)$. It was observed that a-chymotrypsin considerably reduces the gelation time from 8 days (or no gelation happened in 2 weeks) to 10 min- $4 \mathrm{~h}$ depending on the structure of amino acid derivatives . Nanofibers are produced by Fmoc-amino acid and amino acid, which were created by the hydrolysis of the amino acid ester. The outcomes showed that the enzyme-substrate interactions are essential for promoting the supramolecular self-assembly of these amino acid derivatives into fibrous hydrogels. The results reveal that the transparent hydrogels comprised of long nanofibers with about $20 \mathrm{~nm}$ in diameter.

Xie et al. reported an a-chymotrypsin promoted self-assembly method through the enzymesubstrate interactions for the synthesis of supramolecular hydrogels. Mainly, some easily accessible amino acid derivatives, like Fmoc-F, Fmoc-W, F-OMe, F-OEt andY-OMe were selected as building blocks to produce well-defined nanofibers as the matrices of hydrogels (163). Furthermore, they revealed that instead of the enzymatic synthesis of hydrogelators, the 
enzyme-substrate interactions promoted the self-assembly of amino acid derivatives into supramolecular hydrogels. This mechanism is similar to the ligand-receptor interaction that catalyzed aggregation (161). However, it is considerably different from that in terms of the enzyme-assisted self-assembly, which engages the enzymatic synthesis or the hydrolysis procedure $(68,164,165)$. Also, they showed that co-assembly most probably occurred in this system proved by the compositional analysis of the supramolecular scaffolds.

\section{Conclusions and future outlook}

Enzymatic crosslinking reactions are a mild and useful method to form hydrogels in situ. Characteristics like gelation rate, hydrogel stiffness, and cytocompatibility are essential factors to consider when choosing a suitable enzymatic system for any biomedical application. Rapid gelation ensures a localized gel formation and it is suitable for drug delivery and tissue adhesives. Slow gelation permits the filling of irregularly shaped wounds with gel precursors, resulting in cohesion between the hydrogel and the surrounding native tissue. Changing the crosslinking density can also modify the release rate of the encapsulated proteins. Transglutaminase, tyrosinase, sortase A, phosphopantetheinyl transferase, lysyl oxidase, plasma amine oxidase, phosphatases, thermolysin, b-lactamase, phosphatase/ kinase, peroxidases, and achymotrypsin have been studied, and each one has potential properties to perform crosslink reaction to form suitable hydrogels. The discriped enzymatic hydrogelations indicate promising approaches for clinical applications of hydrogels crosslinked by enzyme-mediated oxidative reaction. Enzyme-mediated crosslinking reaction coupled with bioprinting technologies is an innovative prospective in tissue engineering and other biomedical applications, which provides the ability to produce much more precise biomedical products in a short time. The versatile 
enzymatic hydrogel properties can guide us to investigate better novel approaches for biomedical purposes.

\section{References}

1. Kharkar PM, Kiick KL, Kloxin AM. Designing degradable hydrogels for orthogonal control of cell microenvironments. Chemical Society Reviews. 2013;42(17):7335-72.

2. El-Sherbiny IM, Yacoub MH. Hydrogel scaffolds for tissue engineering: Progress and challenges. Global Cardiology Science and Practice. 2013:38.

3. Bahrami N, Bayat M, Farzin A, Sadredin Hajseyedjavadi M, Goodarzi A, Salehi M, et al. The Ability of 3D Alginate/Polyvinyl Alcohol Cross-Linked Hybrid Hydrogel to Differentiate Periodontal Ligament Stem Cells Into Osteoblasts. Archives of Neuroscience. 2019;6(2).

4. Fathi A, Khanmohammadi M, Goodarzi A, Mobarakeh ZT, Saremi J, Arabpour Z, et al. Fabrication of Chitosan-Polyvinyl Alcohol and Silk Electrospun Fiber Seeded with Differentiated Keratinocyte for Skin Tissue Regeneration in Animal Wound Model. 2020.

5. Nooshabadi VT, Khanmohamadi M, Valipour E, Mahdipour S, Salati A, Malekshahi ZV, et al. Impact of exosome loaded chitosan hydrogel in wound repair and layered dermal reconstitution in mice animal model. Journal of Biomedical Materials Research Part A. 2020.

6. Shafei S, Khanmohammadi M, Heidari R, Ghanbari H, Taghdiri Nooshabadi V, Farzamfar S, et al. Exosome loaded alginate hydrogel promotes tissue regeneration in full-thickness skin wounds: An in vivo study. Journal of Biomedical Materials Research Part A. 2020;108(3):545-56.

7. Tomita K, Sakai S, Khanmohammadi M, Yamochi T, Hashimoto S, Anzai M, et al. Cryopreservation of a small number of human sperm using enzymatically fabricated, hollow hyaluronan microcapsules handled by conventional ICSI procedures. Journal of assisted reproduction and genetics. 2016;33(4):501-11.

8. Khanmohammadi M, Dastjerdi MB, Ai A, Ahmadi A, Godarzi A, Rahimi A, et al. Horseradish peroxidase-catalyzed hydrogelation for biomedical applications. Biomaterials science. 2018;6(6):128698.

9. Annabi N, Tamayol A, Uquillas JA, Akbari M, Bertassoni LE, Cha C, et al. 25th anniversary article: Rational design and applications of hydrogels in regenerative medicine. Advanced materials. 2014;26(1):85-124.

10. Gohil S, Hanna C, Nair L. Injectable hydrogels by enzymatic crosslinking. Injectable Hydrogels for Regenerative Engineering: Imperial College Press London; 2016. p. 201-38.

11. Kobayashi S, Uyama H, Kimura S. Enzymatic polymerization. Chemical Reviews. 2001;101(12):3793-818.

12. Teixeira LSM, Feijen J, van Blitterswijk CA, Dijkstra PJ, Karperien M. Enzyme-catalyzed crosslinkable hydrogels: emerging strategies for tissue engineering. Biomaterials. 2012;33(5):1281-90.

13. Sakai S, Nakahata M. Horseradish peroxidase catalyzed hydrogelation for biomedical, biopharmaceutical, and biofabrication applications. Chemistry-An Asian Journal. 2017;12(24):3098-109.

14. Jin R, Moreira Teixeira LS, Dijkstra PJ, Zhong Z, van Blitterswijk CA, Karperien M, et al. Enzymatically crosslinked dextran-tyramine hydrogels as injectable scaffolds for cartilage tissue engineering. Tissue Engineering Part A. 2010;16(8):2429-40. 
15. Greenberg CS, Birckbichler PJ, Rice RH. Transglutaminases: multifunctional cross-linking enzymes that stabilize tissues. The FASEB Journal. 1991;5(15):3071-7.

16. Ando $H$, Adachi $M$, Umeda $K$, Matsuura $A$, Nonaka $M$, Uchio $R$, et al. Purification and characteristics of a novel transglutaminase derived from microorganisms. Agricultural and Biological Chemistry. 1989;53(10):2613-7.

17. Savoca MP, Tonoli E, Atobatele AG, Verderio EA. Biocatalysis by transglutaminases: a review of biotechnological applications. Micromachines. 2018;9(11):562.

18. Davis NE, Ding S, Forster RE, Pinkas DM, Barron AE. Modular enzymatically crosslinked protein polymer hydrogels for in situ gelation. Biomaterials. 2010;31(28):7288-97.

19. Domeradzka NE, Werten MW, de Wolf FA, de Vries R. Protein cross-linking tools for the construction of nanomaterials. Current opinion in biotechnology. 2016;39:61-7.

20. Pisano J, Finlayson J, Peyton MP. Cross-link in fibrin polymerized by factor XIII: $\varepsilon$-( $\gamma$-glutamyl) lysine. Science. 1968;160(3830):892-3.

21. Kim S-Y, Grant P, Lee J-H, Pant HC, Steinert PM. Differential expression of multiple transglutaminases in human brain Increased expression and cross-linking by transglutaminases 1 and 2 in Alzheimer's disease. Journal of Biological Chemistry. 1999;274(43):30715-21.

22. Priglinger SG, Alge CS, Kook D, Thiel M, Schumann R, Eibl K, et al. Potential role of tissue transglutaminase in glaucoma filtering surgery. Investigative ophthalmology \& visual science. 2006;47(9):3835-45.

23. Priglinger SG, Alge CS, Kreutzer TC, Neubauer AS, Haritoglou C, Kampik A, et al. Keratinocyte transglutaminase in proliferative vitreoretinopathy. Investigative ophthalmology \& visual science. 2006;47(11):4990-7.

24. Griffin M, Casadio R, Bergamini CM. Transglutaminases: nature's biological glues. Biochemical Journal. 2002;368(2):377-96.

25. Eyrich D, Brandl F, Appel B, Wiese H, Maier G, Wenzel M, et al. Long-term stable fibrin gels for cartilage engineering. Biomaterials. 2007;28(1):55-65.

26. Hall H, Baechi T, Hubbell JA. Molecular properties of fibrin-based matrices for promotion of angiogenesis in vitro. Microvascular research. 2001;62(3):315-26.

27. Peretti GM, Xu J-W, Bonassar LJ, Kirchhoff CH, Yaremchuk MJ, Randolph MA. Review of injectable cartilage engineering using fibrin gel in mice and swine models. Tissue engineering. 2006;12(5):1151-68.

28. Schense JC, Bloch J, Aebischer P, Hubbell JA. Enzymatic incorporation of bioactive peptides into fibrin matrices enhances neurite extension. Nature biotechnology. 2000;18(4):415-9.

29. Sala A, Ehrbar M, Trentin D, Schoenmakers RG, Vörös J, Weber FE. Enzyme mediated sitespecific surface modification. Langmuir. 2010;26(13):11127-34.

30. Jürgensen K, Aeschlimann D, Cavin V, Genge M, Hunziker E. A New Biological Glue for CartilageCartilage Interfaces: Tissue Transglutaminase*. J Bone Joint Surg Am. 1997;79(2):185-93.

31. Sperinde JJ, Griffith LG. Control and prediction of gelation kinetics in enzymatically cross-linked poly (ethylene glycol) hydrogels. Macromolecules. 2000;33(15):5476-80.

32. Sperinde JJ, Griffith LG. Synthesis and characterization of enzymatically-cross-linked poly (ethylene glycol) hydrogels. Macromolecules. 1997;30(18):5255-64.

33. Hu BH, Messersmith P. Enzymatically cross-linked hydrogels and their adhesive strength to biosurfaces. Orthodontics \& craniofacial research. 2005;8(3):145-9.

34. Yung CW, Bentley WE, Barbari TA. Diffusion of interleukin-2 from cells overlaid with cytocompatible enzyme-crosslinked gelatin hydrogels. Journal of Biomedical Materials Research Part A. 2010;95(1):25-32.

35. Yung C, Wu L, Tullman J, Payne G, Bentley W, Barbari T. Transglutaminase crosslinked gelatin as a tissue engineering scaffold. Journal of Biomedical Materials Research Part A. 2007;83(4):1039-46. 
36. McHale MK, Setton LA, Chilkoti A. Synthesis and in vitro evaluation of enzymatically cross-linked elastin-like polypeptide gels for cartilaginous tissue repair. Tissue engineering. 2005;11(11-12):1768-79.

37. Jones MER, Messersmith PB. Facile coupling of synthetic peptides and peptide-polymer conjugates to cartilage via transglutaminase enzyme. Biomaterials. 2007;28(35):5215-24.

38. Chen T, Small DA, McDermott MK, Bentley WE, Payne GF. Enzymatic methods for in situ cell entrapment and cell release. Biomacromolecules. 2003;4(6):1558-63.

39. Wu L-Q, Bentley WE, Payne GF. Biofabrication with biopolymers and enzymes: potential for constructing scaffolds from soft matter. The International journal of artificial organs. 2011;34(2):215-24.

40. Yamamoto $H$, Kuno S, Nagai A, Nishida A, Yamauchi S, Ikeda K. Insolubilizing and adhesive studies of water-soluble synthetic model proteins. International journal of biological macromolecules. 1990;12(5):305-10.

41. Chen T, Embree HD, Brown EM, Taylor MM, Payne GF. Enzyme-catalyzed gel formation of gelatin and chitosan: potential for in situ applications. Biomaterials. 2003;24(17):2831-41.

42. Chen T, Embree HD, Wu LQ, Payne GF. In vitro protein-polysaccharide conjugation: Tyrosinasecatalyzed conjugation of gelatin and chitosan. Biopolymers. 2002;64(6):292-302.

43. Yamada K, Chen T, Kumar G, Vesnovsky O, Topoleski LT, Payne GF. Chitosan based waterresistant adhesive. Analogy to mussel glue. Biomacromolecules. 2000;1(2):252-8.

44. Demolliens A, Boucher C, Durocher Y, Jolicoeur M, Buschmann MD, De Crescenzo G. Tyrosinasecatalyzed synthesis of a universal coil-chitosan bioconjugate for protein immobilization. Bioconjugate chemistry. 2008;19(9):1849-54.

45. Anghileri A, Lantto R, Kruus K, Arosio C, Freddi G. Tyrosinase-catalyzed grafting of sericin peptides onto chitosan and production of protein-polysaccharide bioconjugates. Journal of biotechnology. 2007;127(3):508-19.

46. Freddi G, Anghileri A, Sampaio S, Buchert J, Monti P, Taddei P. Tyrosinase-catalyzed modification of Bombyx mori silk fibroin: grafting of chitosan under heterogeneous reaction conditions. Journal of biotechnology. 2006;125(2):281-94.

47. Mishra D, Bhunia B, Banerjee I, Datta P, Dhara S, Maiti TK. Enzymatically crosslinked carboxymethyl-chitosan/gelatin/nano-hydroxyapatite injectable gels for in situ bone tissue engineering application. Materials Science and Engineering: C. 2011;31(7):1295-304.

48. Joshi AK, Zhang L, Rangan VS, Smith S. Cloning, expression, and characterization of a human 4'phosphopantetheinyl transferase with broad substrate specificity. Journal of Biological Chemistry. 2003;278(35):33142-9.

49. Mosiewicz KA, Johnsson K, Lutolf MP. Phosphopantetheinyl transferase-catalyzed formation of bioactive hydrogels for tissue engineering. Journal of the American Chemical Society. 2010;132(17):5972-4.

50. D'Souza SE, Ginsberg MH, Plow EF. Arginyl-glycyl-aspartic acid (RGD): a cell adhesion motif. Trends in biochemical sciences. 1991;16:246-50.

51. Ton-That H, Liu G, Mazmanian SK, Faull KF, Schneewind O. Purification and characterization of sortase, the transpeptidase that cleaves surface proteins of Staphylococcus aureus at the LPXTG motif. Proceedings of the National Academy of Sciences. 1999;96(22):12424-9.

52. Mao H, Hart SA, Schink A, Pollok BA. Sortase-mediated protein ligation: a new method for protein engineering. Journal of the American Chemical Society. 2004;126(9):2670-1.

53. Cambria E, Renggli K, Ahrens CC, Cook CD, Kroll C, Krueger AT, et al. Covalent Modification of Synthetic Hydrogels with Bioactive Proteins via Sortase-Mediated Ligation. Biomacromolecules. 2015;16(8):2316-26.

54. Bakota EL, Aulisa L, Galler KM, Hartgerink JD. Enzymatic cross-linking of a nanofibrous peptide hydrogel. Biomacromolecules. 2010;12(1):82-7. 
55. Kagan HM, Li W. Lysyl oxidase: properties, specificity, and biological roles inside and outside of the cell. Journal of cellular biochemistry. 2003;88(4):660-72.

56. Kothapalli CR, Ramamurthi A. Lysyl oxidase enhances elastin synthesis and matrix formation by vascular smooth muscle cells. Journal of tissue engineering and regenerative medicine. 2009;3(8):65561.

57. Lau Y-KI, Gobin AM, West JL. Overexpression of lysyl oxidase to increase matrix crosslinking and improve tissue strength in dermal wound healing. Annals of biomedical engineering. 2006;34(8):123946.

58. Hwang JJ, Stupp SI. Poly (amino acid) bioadhesives for tissue repair. Journal of Biomaterials Science, Polymer Edition. 2000;11(10):1023-38.

59. Grieshaber SE, Nie T, Yan C, Zhong S, Teller SS, Clifton RJ, et al. Assembly Properties of an Alanine-Rich, Lysine-Containing Peptide and the Formation of Peptide/Polymer Hybrid Hydrogels. Macromolecular chemistry and physics. 2011;212(3):229-39.

60. Gao Y, Kuang Y, Guo Z-F, Guo Z, Krauss IJ, Xu B. Enzyme-instructed molecular self-assembly confers nanofibers and a supramolecular hydrogel of taxol derivative. Journal of the American Chemical Society. 2009;131(38):13576-7.

61. Yang Z, Liang G, Xu B. Enzymatic hydrogelation of small molecules. Accounts of chemical research. 2008;41(2):315-26.

62. Yang Z, Gu H, Fu D, Gao P, Lam JK, Xu B. Enzymatic formation of supramolecular hydrogels. Advanced materials. 2004;16(16):1440-4.

63. Toledano S, Williams RJ, Jayawarna V, Ulijn RV. Enzyme-triggered self-assembly of peptide hydrogels via reversed hydrolysis. Journal of the American Chemical Society. 2006;128(4):1070-1.

64. Yang $\mathrm{Z}$, Ho P-L, Liang $\mathrm{G}$, Chow $\mathrm{KH}$, Wang $\mathrm{Q}$, Cao $\mathrm{Y}$, et al. Using $\beta$-lactamase to trigger supramolecular hydrogelation. Journal of the American Chemical Society. 2007;129(2):266-7.

65. Yang Z, Liang G, Guo Z, Guo Z, Xu B. Intracellular hydrogelation of small molecules inhibits bacterial growth. Angewandte Chemie International Edition. 2007;46(43):8216-9.

66. Yang Z, Liang G, Wang L, Xu B. Using a kinase/phosphatase switch to regulate a supramolecular hydrogel and forming the supramolecular hydrogel in vivo. Journal of the American Chemical Society. 2006;128(9):3038-43.

67. Williams RJ, Mart RJ, Ulijn RV. Exploiting biocatalysis in peptide self-assembly. Peptide Science. 2010;94(1):107-17.

68. Williams RJ, Smith AM, Collins R, Hodson N, Das AK, Ulijn RV. Enzyme-assisted self-assembly under thermodynamic control. Nature nanotechnology. 2009;4(1):19-24.

69. Schnepp ZA, Gonzalez-McQuire R, Mann S. Hybrid Biocomposites Based on Calcium Phosphate Mineralization of Self-Assembled Supramolecular Hydrogels. Advanced Materials. 2006;18(14):1869-72.

70. Yuan D, Shi J, Du X, Huang Y, Gao Y, Xu B. Enzyme-instructed assembly of the core of yeast prion Sup35 to form supramolecular hydrogels. Journal of Materials Chemistry B. 2016.

71. Toda H, Yamamoto M, Uyama H, Tabata Y. Fabrication of hydrogels with elasticity changed by alkaline phosphatase for stem cell culture. Acta biomaterialia. 2016;29:215-27.

72. Ryan BJ, Carolan N, Ó'Fágáin C. Horseradish and soybean peroxidases: comparable tools for alternative niches? Trends in biotechnology. 2006;24(8):355-63.

73. Sakai S, Khanmohammadi M, Khoshfetrat AB, Taya M. Horseradish peroxidase-catalyzed formation of hydrogels from chitosan and poly (vinyl alcohol) derivatives both possessing phenolic hydroxyl groups. Carbohydrate polymers. 2014;111:404-9.

74. Khanmohammadi M, Sakai S, Ashida T, Taya M. Production of hyaluronic-acid-based cellenclosing microparticles and microcapsules via enzymatic reaction using a microfluidic system. Journal of Applied Polymer Science. 2016;133(16). 
75. Tran NQ, Joung YK, Lih E, Park KM, Park KD. Supramolecular hydrogels exhibiting fast in situ gel forming and adjustable degradation properties. Biomacromolecules. 2010;11(3):617-25.

76. Sofia SJ, Singh A, Kaplan DL. Peroxidase-catalyzed crosslinking of functionalized polyaspartic acid polymers. Journal of Macromolecular Science, Part A. 2002;39(10):1151-81.

77. Kurisawa M, Chung JE, Yang YY, Gao SJ, Uyama H. Injectable biodegradable hydrogels composed of hyaluronic acid-tyramine conjugates for drug delivery and tissue engineering. Chemical communications. 2005(34):4312-4.

78. Bagheri S, Bagher Z, Hassanzadeh S, Simorgh S, Kamrava SK, Taghdiri Nooshabadi V, et al. Control of cellular adhesiveness in hyaluronic acid-based hydrogel through varying degrees of phenol moiety crosslinking. Journal of Biomedical Materials Research Part A.

79. Wang L-S, Chung JE, Chan PP-Y, Kurisawa M. Injectable biodegradable hydrogels with tunable mechanical properties for the stimulation of neurogenesic differentiation of human mesenchymal stem cells in 3D culture. Biomaterials. 2010;31(6):1148-57.

80. Khanmohammadi M, Sakai S, Taya M. Fabrication of single and bundled filament-like tissues using biodegradable hyaluronic acid-based hollow hydrogel fibers. International journal of biological macromolecules. 2017;104:204-12.

81. Khanmohammadi M, Sakai S, Taya M. Impact of immobilizing of low molecular weight hyaluronic acid within gelatin-based hydrogel through enzymatic reaction on behavior of enclosed endothelial cells. International journal of biological macromolecules. 2017;97:308-16.

82. Jin R, Hiemstra C, Zhong Z, Feijen J. Enzyme-mediated fast in situ formation of hydrogels from dextran-tyramine conjugates. Biomaterials. 2007;28(18):2791-800.

83. Sakai S, Yamada Y, Zenke T, Kawakami K. Novel chitosan derivative soluble at neutral pH and insitu gellable via peroxidase-catalyzed enzymatic reaction. Journal of Materials Chemistry. 2009;19(2):230-5.

84. Khoshfetrat AB, Khanmohammadi M, Sakai S, Taya M. Enzymatically-gellable galactosylated chitosan: Hydrogel characteristics and hepatic cell behavior. International journal of biological macromolecules. 2016;92:892-9.

85. Sakai S, Liu Y, Mah EJ, Taya M. Horseradish peroxidase/catalase-mediated cell-laden alginatebased hydrogel tube production in two-phase coaxial flow of aqueous solutions for filament-like tissues fabrication. Biofabrication. 2013;5(1):015012.

86. Khanmohammadi M, Zolfagharzadeh V, Bagher Z, Soltani H, Ai J. Cell encapsulation in core-shell microcapsules through coaxial electrospinning system and horseradish peroxidase-catalyzed crosslinking. Biomedical Physics \& Engineering Express. 2020;6(1):015022.

87. Kuzmenko V, Hägg D, Toriz G, Gatenholm P. In situ forming spruce xylan-based hydrogel for cell immobilization. Carbohydrate polymers. 2014;102:862-8.

88. Ogushi Y, Sakai S, Kawakami K. Synthesis of enzymatically-gellable carboxymethylcellulose for biomedical applications. Journal of bioscience and bioengineering. 2007;104(1):30-3.

89. Park KM, Shin YM, Joung YK, Shin H, Park KD. In situ forming hydrogels based on tyramine conjugated 4-Arm-PPO-PEO via enzymatic oxidative reaction. Biomacromolecules. 2010;11(3):706-12.

90. Sun Y, Deng Z, Tian Y, Lin C. Horseradish peroxidase-mediated in situ forming hydrogels from degradable tyramine-based poly (amido amine) s. Journal of Applied Polymer Science. 2013;127(1):40-8.

91. Lee $\mathrm{F}, \mathrm{Bae} \mathrm{KH}$, Kurisawa M. Injectable hydrogel systems crosslinked by horseradish peroxidase. Biomedical Materials. 2015;11(1):014101.

92. Liu Y, Sakai S, Kawa S, Taya M. Identification of Hydrogen Peroxide-Secreting Cells by Cytocompatible Coating with a Hydrogel Membrane. Analytical chemistry. 2014;86(23):11592-8.

93. Sakai S, Taya M. On-cell surface cross-linking of polymer molecules by horseradish peroxidase anchored to cell membrane for individual cell encapsulation in hydrogel sheath. ACS Macro Letters. 2014;3(10):972-5. 
94. Darr A, Calabro A. Synthesis and characterization of tyramine-based hyaluronan hydrogels. Journal of Materials Science: Materials in Medicine. 2009;20(1):33-44.

95. Lee $F$, Chung JE, Kurisawa M. An injectable hyaluronic acid-tyramine hydrogel system for protein delivery. Journal of Controlled Release. 2009;134(3):186-93.

96. Jin R, Teixeira LSM, Dijkstra PJ, van Blitterswijk CA, Karperien M, Feijen J. Chondrogenesis in injectable enzymatically crosslinked heparin/dextran hydrogels. Journal of controlled release. 2011;152(1):186-95.

97. Jin R, Teixeira LM, Dijkstra P, Van Blitterswijk C, Karperien M, Feijen J. Enzymatically-crosslinked injectable hydrogels based on biomimetic dextran-hyaluronic acid conjugates for cartilage tissue engineering. Biomaterials. 2010;31(11):3103-13.

98. Kim KS, Park SJ, Yang J-A, Jeon J-H, Bhang SH, Kim B-S, et al. Injectable hyaluronic acid-tyramine hydrogels for the treatment of rheumatoid arthritis. Acta biomaterialia. 2011;7(2):666-74.

99. Veitch NC. Horseradish peroxidase: a modern view of a classic enzyme. Phytochemistry. 2004;65(3):249-59.

100. Rodríguez-López JN, Lowe DJ, Hernández-Ruiz J, Hiner AN, García-Cánovas F, Thorneley RN. Mechanism of reaction of hydrogen peroxide with horseradish peroxidase: Identification of intermediates in the catalytic cycle. Journal of the American Chemical Society. 2001;123(48):11838-47.

101. Dunford HB. Peroxidases and catalases: biochemistry, biophysics, biotechnology and physiology: John Wiley \& Sons; 2010.

102. Musso H. Phenol oxidation reactions. Angewandte Chemie International Edition in English. 1963;2(12):723-35.

103. Lee F, Chung JE, Kurisawa M. An injectable enzymatically crosslinked hyaluronic acid-tyramine hydrogel system with independent tuning of mechanical strength and gelation rate. Soft Matter. 2008;4(4):880-7.

104. Schmidt A, Schumacher JT, Reichelt J, Hecht H-J, Bilitewski U. Mechanistic and molecular investigations on stabilization of horseradish peroxidase C. Analytical chemistry. 2002;74(13):3037-45.

105. Huang Q, Huang Q, Pinto RA, Griebenow K, Schweitzer-Stenner R, Weber WJ. Inactivation of horseradish peroxidase by phenoxyl radical attack. Journal of the American Chemical Society. 2005;127(5):1431-7.

106. Kurisawa M, Lee F, Wang L-S, Chung JE. Injectable enzymatically crosslinked hydrogel system with independent tuning of mechanical strength and gelation rate for drug delivery and tissue engineering. Journal of Materials Chemistry. 2010;20(26):5371-5.

107. Engberg K, Frank CW. Protein diffusion in photopolymerized poly (ethylene glycol) hydrogel networks. Biomedical Materials. 2011;6(5):055006.

108. van de Wetering P, Metters AT, Schoenmakers RG, Hubbell JA. Poly (ethylene glycol) hydrogels formed by conjugate addition with controllable swelling, degradation, and release of pharmaceutically active proteins. Journal of Controlled Release. 2005;102(3):619-27.

109. Leach JB, Schmidt CE. Characterization of protein release from photocrosslinkable hyaluronic acid-polyethylene glycol hydrogel tissue engineering scaffolds. Biomaterials. 2005;26(2):125-35.

110. Xu K, Lee F, Gao SJ, Chung JE, Yano H, Kurisawa M. Injectable hyaluronic acid-tyramine hydrogels incorporating interferon- $\alpha 2 a$ for liver cancer therapy. Journal of Controlled Release. 2013;166(3):20310.

111. Sakiyama-Elbert SE, Hubbell JA. Development of fibrin derivatives for controlled release of heparin-binding growth factors. Journal of Controlled Release. 2000;65(3):389-402.

112. Choi JH, Jang JY, Joung YK, Kwon MH, Park KD. Intracellular delivery and anti-cancer effect of self-assembled heparin-Pluronic nanogels with RNase A. Journal of Controlled Release. 2010;147(3):4207. 
113. DeVolder R, Antoniadou E, Kong H. Enzymatically cross-linked injectable alginate-g-pyrrole hydrogels for neovascularization. Journal of controlled release. 2013;172(1):30-7.

114. Dehghan-Niri M, Tavakol M, Vasheghani-Farahani E, Ganji F. Drug release from enzymemediated in situ-forming hydrogel based on gum tragacanth-tyramine conjugate. Journal of biomaterials applications. 2015;29(10):1343-50.

115. Engler AJ, Sen S, Sweeney HL, Discher DE. Matrix elasticity directs stem cell lineage specification. Cell. 2006;126(4):677-89.

116. Ghosh K, Ingber DE. Micromechanical control of cell and tissue development: implications for tissue engineering. Advanced drug delivery reviews. 2007;59(13):1306-18.

117. Bae JW, Choi JH, Lee Y, Park KD. Horseradish peroxidase-catalysed in situ-forming hydrogels for tissue-engineering applications. Journal of tissue engineering and regenerative medicine. 2015;9(11):1225-32.

118. Wang L-S, Boulaire J, Chan PP, Chung JE, Kurisawa M. The role of stiffness of gelatinhydroxyphenylpropionic acid hydrogels formed by enzyme-mediated crosslinking on the differentiation of human mesenchymal stem cell. Biomaterials. 2010;31(33):8608-16.

119. Lim TC, Toh WS, Wang L-S, Kurisawa M, Spector M. The effect of injectable gelatinhydroxyphenylpropionic acid hydrogel matrices on the proliferation, migration, differentiation and oxidative stress resistance of adult neural stem cells. Biomaterials. 2012;33(12):3446-55.

120. Sharma RK, Zhou Q, Netland PA. Effect of oxidative preconditioning on neural progenitor cells. Brain research. 2008;1243:19-26.

121. White BC, Sullivan JM, DeGracia DJ, O’Neil BJ, Neumar RW, Grossman LI, et al. Brain ischemia and reperfusion: molecular mechanisms of neuronal injury. Journal of the neurological sciences. 2000;179(1):1-33.

122. Wang L-S, Du C, Toh WS, Wan AC, Gao SJ, Kurisawa M. Modulation of chondrocyte functions and stiffness-dependent cartilage repair using an injectable enzymatically crosslinked hydrogel with tunable mechanical properties. Biomaterials. 2014;35(7):2207-17.

123. Toh WS, Lim TC, Kurisawa M, Spector M. Modulation of mesenchymal stem cell chondrogenesis in a tunable hyaluronic acid hydrogel microenvironment. Biomaterials. 2012;33(15):3835-45.

124. Amini AA, Nair LS. Recombinant human lactoferrin as a biomaterial for bone tissue engineering: mechanism of antiapoptotic and osteogenic activity. Advanced healthcare materials. 2014;3(6):897-905.

125. Teixeira LSM, Bijl S, Pully VV, Otto C, Jin R, Feijen J, et al. Self-attaching and cell-attracting in-situ forming dextran-tyramine conjugates hydrogels for arthroscopic cartilage repair. Biomaterials. 2012;33(11):3164-74.

126. Kuo K-C, Lin R-Z, Tien H-W, Wu P-Y, Li Y-C, Melero-Martin JM, et al. Bioengineering vascularized tissue constructs using an injectable cell-laden enzymatically crosslinked collagen hydrogel derived from dermal extracellular matrix. Acta biomaterialia. 2015;27:151-66.

127. Sakai S, Liu Y, Sengoku M, Taya M. Cell-selective encapsulation in hydrogel sheaths via biospecific identification and biochemical cross-linking. Biomaterials. 2015;53:494-501.

128. Morelli A, Betti M, Puppi D, Bartoli C, Gazzarri M, Chiellini F. Enzymatically Crosslinked Ulvan Hydrogels as Injectable Systems for Cell Delivery. Macromolecular Chemistry and Physics. 2015.

129. WARTENBERG M, DÖNMEZ F, LING FC, ACKER H, HESCHELER J, SAUER H. Tumor-induced angiogenesis studied in confrontation cultures of multicellular tumor spheroids and embryoid bodies grown from pluripotent embryonic stem cells. The FASEB Journal. 2001;15(6):995-1005.

130. Hirschhaeuser F, Menne H, Dittfeld C, West J, Mueller-Klieser W, Kunz-Schughart LA. Multicellular tumor spheroids: an underestimated tool is catching up again. Journal of biotechnology. 2010;148(1):3-15.

131. De Ridder L, Cornelissen M, De Ridder D. Autologous spheroid culture: a screening tool for human brain tumour invasion. Critical reviews in oncology/hematology. 2000;36(2):107-22. 
132. Liu Y, Sakai S, Taya M. Engineering tissues with a perfusable vessel-like network using endothelialized alginate hydrogel fiber and spheroid-enclosing microcapsules. Heliyon. 2016;2(2):e00067.

133. Tomita K, Sakai S, Khanmohammadi M, Yamochi T, Hashimoto S, Anzai $M$, et al. Cryopreservation of a small number of human sperm using enzymatically fabricated, hollow hyaluronan microcapsules handled by conventional ICSI procedures. Journal of assisted reproduction and genetics. 2016:1-11.

134. Spotnitz WD, Burks S. Hemostats, sealants, and adhesives: components of the surgical toolbox. Transfusion. 2008;48(7):1502-16.

135. Brennan M. Blood Reviews,". Fibrin Glue. 1991;5:240-4.

136. Vauthier C, Dubernet C, Fattal E, Pinto-Alphandary H, Couvreur P. Poly (alkylcyanoacrylates) as biodegradable materials for biomedical applications. Advanced drug delivery reviews. 2003;55(4):51948.

137. Lih E, Lee JS, Park KM, Park KD. Rapidly curable chitosan-PEG hydrogels as tissue adhesives for hemostasis and wound healing. Acta biomaterialia. 2012;8(9):3261-9.

138. Jayakumar R, Prabaharan M, Kumar PS, Nair S, Tamura H. Biomaterials based on chitin and chitosan in wound dressing applications. Biotechnology advances. 2011;29(3):322-37.

139. Tran NQ, Joung YK, Lih E, Park KD. In situ forming and rutin-releasing chitosan hydrogels as injectable dressings for dermal wound healing. Biomacromolecules. 2011;12(8):2872-80.

140. Kurisawa M, Chung JE, Uyama H, Kobayashi S. Enzymatic synthesis and antioxidant properties of poly (rutin). Biomacromolecules. 2003;4(5):1394-9.

141. Sakai S, Tsumura M, Inoue M, Koga Y, Fukano K, Taya M. Polyvinyl alcohol-based hydrogel dressing gellable on-wound via a co-enzymatic reaction triggered by glucose in the wound exudate. Journal of Materials Chemistry B. 2013;1(38):5067-75.

142. Zavada S, McHardy N, Scott T. Oxygen-mediated enzymatic polymerization of thiol-ene hydrogels. Journal of Materials Chemistry B. 2014;2(17):2598-605.

143. Zavada SR, Battsengel T, Scott TF. Radical-Mediated Enzymatic Polymerizations. International journal of molecular sciences. 2016;17(2):195.

144. Sakai S, Ueda K, Taya M. Peritoneal adhesion prevention by a biodegradable hyaluronic acidbased hydrogel formed in situ through a cascade enzyme reaction initiated by contact with body fluid on tissue surfaces. Acta biomaterialia. 2015;24:152-8.

145. Bardor M, Faveeuw C, Fitchette A-C, Gilbert D, Galas L, Trottein F, et al. Immunoreactivity in mammals of two typical plant glyco-epitopes, core $\alpha(1,3)$-fucose and core xylose. Glycobiology. 2003;13(6):427-34.

146. Heinecke JW, Li W, Francis GA, Goldstein JA. Tyrosyl radical generated by myeloperoxidase catalyzes the oxidative cross-linking of proteins. Journal of Clinical Investigation. 1993;91(6):2866.

147. Akkara JA, Wang J, Yang D-P, Gonsalves KE. Hematin-catalyzed polymerization of phenol compounds. Macromolecules. 2000;33(7):2377-82.

148. Sakai S, Moriyama K, Taguchi K, Kawakami K. Hematin is an alternative catalyst to horseradish peroxidase for in situ hydrogelation of polymers with phenolic hydroxyl groups in vivo. Biomacromolecules. 2010;11(8):2179-83.

149. Pierach C, Bossenmaier I, Cardinal R, Weimer M, Watson C. Hematin therapy in porphyric attacks. Klinische Wochenschrift. 1980;58(16):829-32.

150. Bissell DM. Treatment of acute hepatic porphyria with hematin. Journal of hepatology. 1988;6(1):1-7.

151. Kohri M, Fukushima H, Taniguchi T, Nakahira T. Synthesis of polyarbutin by oxidative polymerization using PEGylated hematin as a biomimetic catalyst. Polymer journal. 2010;42(12):952-5. 
152. Byun E, Ryu JH, Lee $H$. Catalyst-mediated yet catalyst-free hydrogels formed by interfacial chemical activation. Chemical Communications. 2014;50(22):2869-72.

153. Bae JW, Kim BY, Lih E, Choi JH, Lee Y, Park KD. In situ formation of enzyme-free hydrogels via ferromagnetic microbead-assisted enzymatic cross-linking. Chemical Communications. 2014;50(89):13710-3.

154. Gardner AM, Xu F-h, Fady C, Jacoby FJ, Duffey DC, Tu Y, et al. Apoptotic vs. nonapoptotic cytotoxicity induced by hydrogen peroxide. Free Radical Biology and Medicine. 1997;22(1):73-83.

155. Gülden M, Jess A, Kammann J, Maser E, Seibert H. Cytotoxic potency of H 2 O 2 in cell cultures: impact of cell concentration and exposure time. Free Radical Biology and Medicine. 2010;49(8):1298305.

156. Jin R, Teixeira LM, Dijkstra PJ, Karperien M, Van Blitterswijk C, Zhong Z, et al. Injectable chitosanbased hydrogels for cartilage tissue engineering. Biomaterials. 2009;30(13):2544-51.

157. Murphy SV, Atala A. 3D bioprinting of tissues and organs. Nature biotechnology. 2014;32(8):77385.

158. Murphy SV, Skardal A, Atala A. Evaluation of hydrogels for bio-printing applications. Journal of Biomedical Materials Research Part A. 2013;101(1):272-84.

159. Hu M, Kurisawa M, Deng R, Teo C-M, Schumacher A, Thong Y-X, et al. Cell immobilization in gelatin-hydroxyphenylpropionic acid hydrogel fibers. Biomaterials. 2009;30(21):3523-31.

160. Hu M, Deng R, Schumacher KM, Kurisawa M, Ye H, Purnamawati K, et al. Hydrodynamic spinning of hydrogel fibers. Biomaterials. 2010;31(5):863-9.

161. Shi J, Du X, Huang Y, Zhou J, Yuan D, Wu D, et al. Ligand-receptor interaction catalyzes the aggregation of small molecules to induce cell necroptosis. Journal of the American Chemical Society. 2014;137(1):26-9.

162. Plunkett KN, Berkowski KL, Moore JS. Chymotrypsin responsive hydrogel: application of a disulfide exchange protocol for the preparation of methacrylamide containing peptides. Biomacromolecules. 2005;6(2):632-7.

163. Xie Y, Huang R, Qi W, Wang Y, Su R, He Z. Enzyme-substrate interactions promote the selfassembly of amino acid derivatives into supramolecular hydrogels. Journal of Materials Chemistry $B$. 2016.

164. Liu H, Li Y, Lyu Z, Wan Y, Li X, Chen H, et al. Enzyme-triggered supramolecular self-assembly of platinum prodrug with enhanced tumor-selective accumulation and reduced systemic toxicity. Journal of Materials Chemistry B. 2014;2(47):8303-9.

165. Jayawarna V, Ali M, Jowitt TA, Miller AF, Saiani A, Gough JE, et al. Nanostructured Hydrogels for Three-Dimensional Cell Culture Through Self-Assembly of Fluorenylmethoxycarbonyl-Dipeptides. Advanced Materials. 2006;18(5):611-4. 